\title{
Use of ENVISAT ASAR Global Monitoring Mode to complement optical data in the mapping of rapid broad-scale flooding in Pakistan
}

\author{
D. O'Grady, M. Leblanc, and D. Gillieson \\ School of Earth and Environmental Sciences, James Cook University, 14-88 McGregor Road, Smithfield, \\ QLD 4878, Australia
}

Received: 31 May 2011 - Published in Hydrol. Earth Syst. Sci. Discuss.: 20 June 2011

Revised: 8 October 2011 - Accepted: 4 November 2011 - Published: 17 November 2011

\begin{abstract}
Envisat ASAR Global Monitoring Mode (GM) data are used to produce maps of the extent of the flooding in Pakistan which are made available to the rapid response effort within $24 \mathrm{~h}$ of acquisition. The high temporal frequency and independence of the data from cloud-free skies makes GM data a viable tool for mapping flood waters during those periods where optical satellite data are unavailable, which may be crucial to rapid response disaster planning, where thousands of lives are affected. Image differencing techniques are used, with pre-flood baseline image backscatter values being deducted from target values to eliminate regions with a permanent flood-like radar response due to volume scattering and attenuation, and to highlight the low response caused by specular reflection by open flood water. The effect of local incidence angle on the received signal is mitigated by ensuring that the deducted image is acquired from the same orbit track as the target image. Poor separability of the water class with land in areas beyond the river channels is tackled using a region-growing algorithm which seeks threshold-conformance from seed pixels at the center of the river channels. The resultant mapped extents are tested against MODIS SWIR data where available, with encouraging results.
\end{abstract}

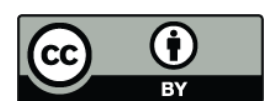

Correspondence to: D. O'Grady (damien.ogrady@my.jcu.edu.au)

\section{Introduction}

Over the 2010 monsoon season, Pakistan saw extensive flooding of the Indus river and its tributaries, which affected over 20 million people, damaging over 2 million hectares of crop land and causing the loss of 1985 lives (NDMA, 2011). Heavy rainfall in the northern regions of the Khyber Pakhtunhwa, reaching $280 \mathrm{~mm}$ on 29 July, damaged major irrigation headworks on the Swat River at Munda, which were built to a discharge capacity of $4.5 \mathrm{Mls}^{-1}$ and which were damaged by the peak discharge of $8.5 \mathrm{Mls}^{-1}$. Further rainfall in Gilgit and Jammu and Kashmir and further south in Balochistan, contributed further to the huge body of water which flooded irrigation channels and agricultural land covering tens of thousands of square kilometers. The UN Food and Agricultural Organization estimate losses of wheat stocks at around 450000 tonnes (Fair, 2011). The Damage Needs Assessment conducted by the World Bank estimated that the recovery from the floods would cost between $\$ 8.7$ and $\$ 10.9$ billion (WBG, 2011).

To facilitate the international relief effort in such crises, maps are made available in near real time by facilities such as NASA's MODIS Rapid Response System, which makes use of the Moderate Resolution Imaging Spectroradiometer (MODIS) on board NASA's Aqua and Terra satellites. Such instruments are, however, limited by the cloud cover that is often present for some time after such flood events. It is largely for this reason that, in recent years, satelliteborne radar instruments have attracted much research into their viability as a means to map flooding, due to their ability to penetrate cloud cover and to their independence from

Published by Copernicus Publications on behalf of the European Geosciences Union. 
the relative position of the sun (Waisurasingha et al., 2007; Wilson and Rashid, 2005; Rosenqvist et al., 2007).

The classification of water with satellite radar data is problematic and error-prone, particularly when some of the main environmental factors affecting the result, such as wind speed and direction and soil moisture, are unknown. The clear advantage of the independence from cloud cover may result in the availability of radar data where more reliable optical data is not available. Revisit time is an important feature of remotely sensed data used for disaster management. The COSMO-SkyMed constellation ${ }^{1}$ comprises a cluster of four $\mathrm{X}$-band SAR sensors on the same orbit path which are capable of a revisit time of less than $12 \mathrm{~h}$. Most radar sensors such as the Advanced Synthetic Aperture Radar (ASAR) aboard the European Space Agency's (ESA) Envisat satellite, and the Phased Array type L-band Synthetic Aperture Radar (PALSAR) on the Japanese Aerospace Exploration Agency's (JAXA) ALOS satellite ${ }^{2}$ have repeat orbit cycles of more than a month, but are able to provide a higher repeat coverage thanks to operation modes which overlap regions at different incidence angles on adjacent orbits. Here we take a closer look at data from the ASAR sensor operating in Global Monitoring (GM) mode, which is systematically acquired when data in other configurations is not required. GM data is made available in near real-time for download to parties with at least a Category-1 fast-track agreement with ESA. The data is available quickly because it is preprocessed at the sensor, before being transmitted down to one of two ground stations in Europe. This is made possible by keeping file sizes and processing requirements low, by using a coarse resolution (pixel size is $500 \mathrm{~m}$, spatial resolution is $1 \mathrm{~km})$. Such a coarse resolution over the full range of incidence angles $\left(12^{\circ}\right.$ to $\left.44^{\circ}\right)$ may prohibit the data's viability as an alternative means to map flooding, but we believe that its temporal frequency and ready availability give the data potential advantages that warrant further investigation. The following questions emerge:

- Is the frequency of GM coverage such that it can provide an alternative source of data to map flooding when cloud cover prohibits the use of optical data?

- Can effects due to factors such as incidence angle be eliminated?

- Will the radiometric uncertainty of signals received from partially and totally inundated areas and nonflooded areas allow the classification of flooding to a level of accuracy sufficient to produce useful maps, given the coarse resolution of GM data?

\footnotetext{
${ }^{1}$ http://www.cosmo-skymed.it/

2 unfortunately recently defunct
}

\section{Study area}

The flood plain of the Indus River occupies nearly half of Pakistan's area. Bounded by the Karakoram, Hindu Kush and Pamir mountain ranges to the north and the Balochistan Plateau to the west, the Indus and its tributaries flow southwards from the northern ranges to the Arabian Sea more than $1000 \mathrm{~km}$ to the south (see Fig. 1).

Having left the ranges, the river falls only a few hundred metres across this distance. Outside of the major cities of Lahore in the north and Karachi in the south, much of Pakistan's population lives close to the Indus and Chenab rivers, farming wheat, cotton, rice and other crops to sustain its population of some 170 million. The 2010 monsoon season saw higher than usual rainfall (Fig. 2 refers), contributing to floods which started affecting populated areas in the north in July and progressed southwards throughout the following months, remaining in some areas throughout October and beyond.

\section{Theoretical basis}

Fundamental choices of radar data rest on wavelength, polarisation configuration, spatial and temporal frequency. Radar signals will interact with their target in a manner dictated by structural, textural and dielectric properties of the target surface. Structural and textural properties are matters of scale, and must be considered in relation to the wavelength of the radar signal. When considering the detection of flood water, we are interested in the radar response from water itself, from the surrounding land cover and, where partial inundation occurs, a combination of the two. The radar response from each of these three categories is a complex combination of effects. In the case of vegetation, C-band radar (wavelength $\lambda=3.75-$ $7.5 \mathrm{~cm}$ ) will tend to interact with small branches and leaves, and L-band $(\lambda=15-30 \mathrm{~cm})$ with larger branches and trunks, each in a scale of order comparable to their own wavelength. Where partial inundation occurs, the radar signal may interact multiple times between the emergent structure (vegetation or buildings, for example), in a phenomenon known as dihedral scattering (or "double-bounce"), resulting in a very high return signal. The extent of this occurrence is dependent, therefore, on the relative scale of the emergent structure with respect to the wavelength of the signal. Where open water is found, if the surface is smooth, much of the radar signal is reflected away from the sensor, resulting in a low backscatter response. The extent of the return signal in this case has a sinusoidal relationship with the angle that the radar is incident to the surface of the water. However, where there are regular waves on the surface of the water, Bragg resonance can result in a very high return signal (e.g. Schaber et al., 1997). The degree to which this occurs depends once again upon the relationship between the scale of the wave and the wavelength of the radar signal. C-band radar is sensitive 


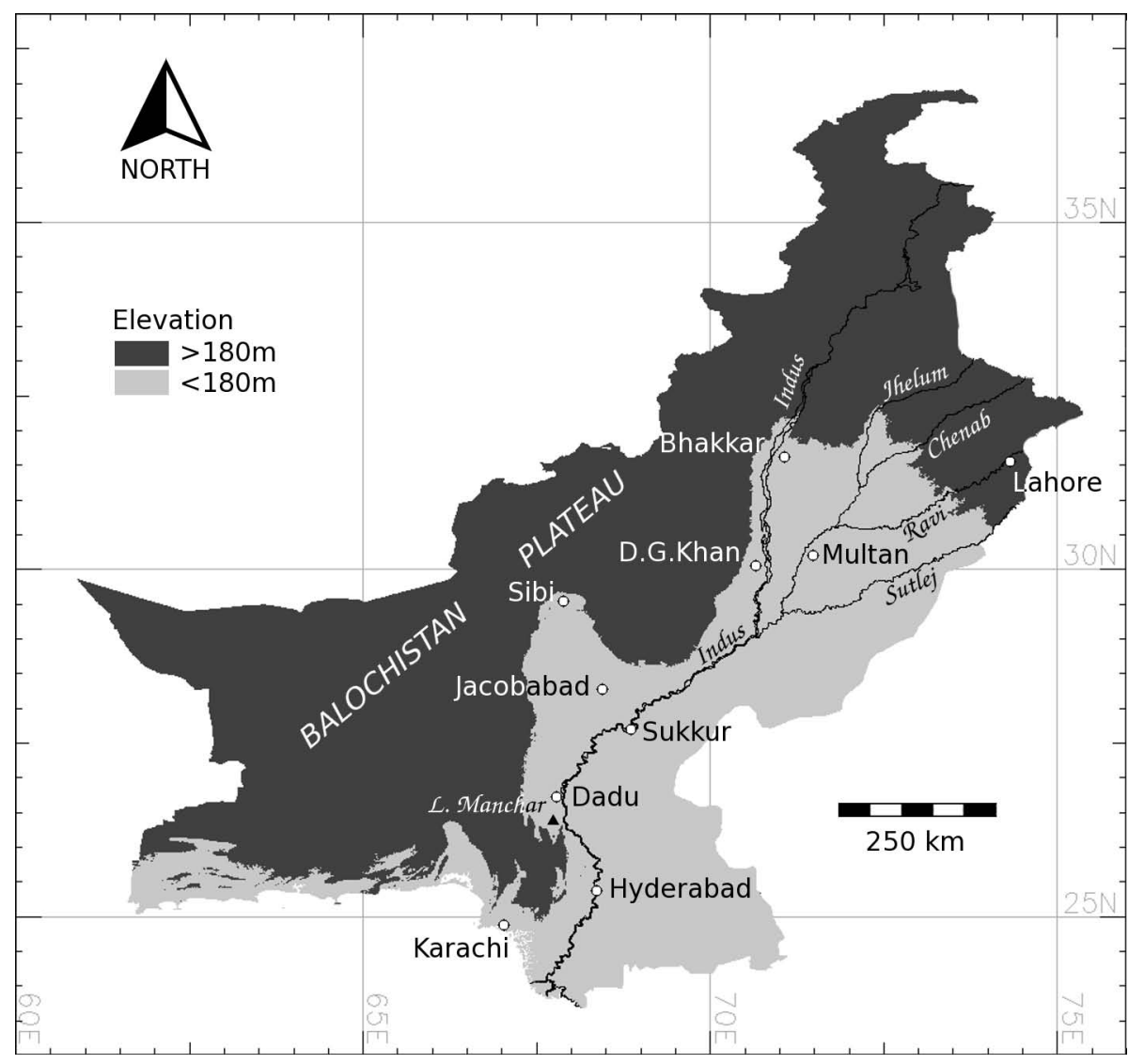

Fig. 1. Pakistan and the Indus-Chenab flood plain.

mainly to small capillary waves and L-band to larger "chop", as might be expected. The alignment of the waves with respect to the direction of the incident radar wave is also important here. The effect is greatest when the incident signal is orthogonal to the alignment of the wave (or parallel to the wind direction), and may not occur at all when the radar signal and the wave direction are parallel (Liebe et al., 2009).Finally, the strength of the radar signal returned to the sensor is reduced by an increasing incidence angle (Monsiváis et al., 2006). Whilst simple geometry allows us to calculate the theoretical degree of this effect, its precise value is the combination of various target characteristics averaged over a pixel-space, and is therefore not readily known for a given time. The change in radar signal for a given degree increase in incidence angle is greater for a specular reflector such as smooth water, than for a diffuse or volume scatterer such as bare soil or vegetation. The particular environment encountered in Pakistan presents a further complication in the detection of flood waters using radar data. Desert areas which remain dry during the flood event absorb and attenuate microwave radiation (Robinson et al., 2006; Schaber et al., 1997), returning a low signal which encroaches into the range of that expected by open water. The difference with the desert response is its relative permanency, and so by deducting values from a GM image taken from the same orbit track prior to the flood, we are able to discern the water from the desert. Digital Numbers (DN) in ASAR detected products correspond to brightness amplitude. The radar backscatter coefficient $\sigma^{0}$ may be calculated from the DN values by:

$\sigma^{0}=\frac{\mathrm{DN}^{2}}{K} \cdot \sin \alpha$

where $K$ is the absolute calibration constant (ESA, 2004). However, the received backscatter is further dependent on $\alpha$ by some function $F$ which is peculiar to the target environmental conditions (Baghdadi et al., 2001; Ulaby et al., 1982) such that

$\sigma_{0}^{0}=\sigma_{\alpha}^{0} \cdot F(\alpha)$

Given a reasonably close temporal separation of images, and in the absence of flooding, the environmental conditions, and therefore the nature of $F$, are similar for a given pixel in the target image to the corresponding pixel in the dry baseline offset.

Converting to decibels and deducting the base backscatter values $\sigma_{\mathrm{b}}^{0}$ from the target values $\sigma_{\mathrm{t}}^{0}$ gives

$$
\Delta \sigma^{0}=10\left[\log \left(\sigma_{\mathrm{t}}^{0}\right)+\log (F(\alpha))-\log \left(\sigma_{\mathrm{b}}^{0}\right)-\log (F(\alpha))\right]
$$



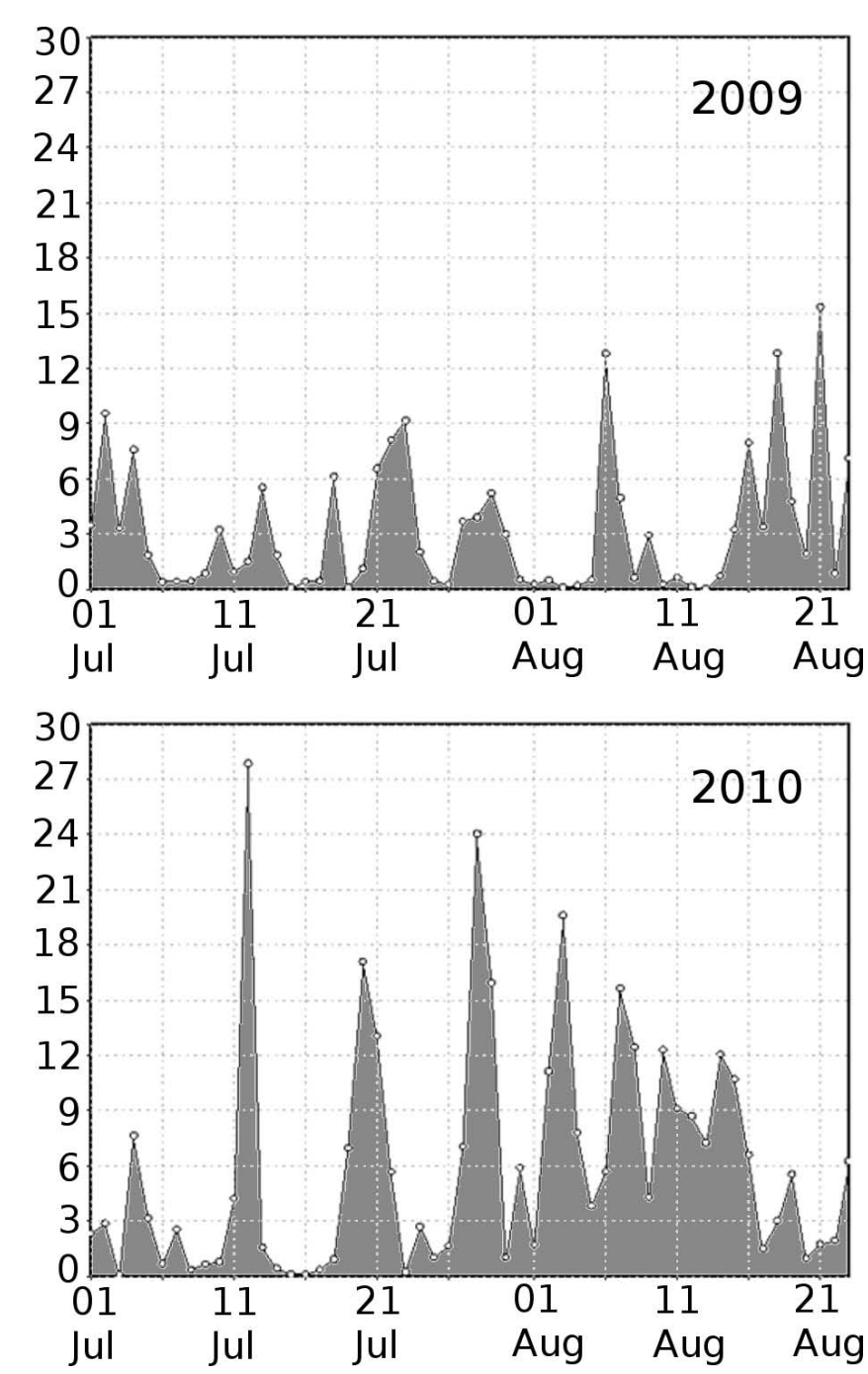

Fig. 2. Daily rainfall $(\mathrm{mm})$ across the Pakistan region (Lat. $28^{\circ} \mathrm{N}-$ $35^{\circ} \mathrm{N}$, Long. $70^{\circ} \mathrm{E}-74^{\circ} \mathrm{E}$ ) in July/August 2009 (above) and 2010 (below). Reproduced from GESDISC (2011).

Substituting Eq. (1) into Eq. (3) gives

$\Delta \sigma^{0}=20 \cdot \log \left(\frac{\mathrm{DN}_{1}}{\mathrm{DN}_{0}}\right)$

This assumes that the difference in $\alpha$ between the two images is negligible. This difference between local incidence angles for the image pairs was found to have a mean value of $-0.02^{\circ}$, with a standard deviation across the region of interest of $0.08^{\circ}$. Taking an extreme case of MEAN $-3 \times$ STDDEV gives a difference of $-0.26^{\circ}$, which would result in an error in the final difference image of $0.02 \mathrm{~dB}$ at $44^{\circ}$ and $0.07 \mathrm{~dB}$ at $15^{\circ}$. Given the radiometric uncertainty in the GM data of 1.54-1.74 dB (ESA, 2007a), such differences may be disregarded for our purposes.

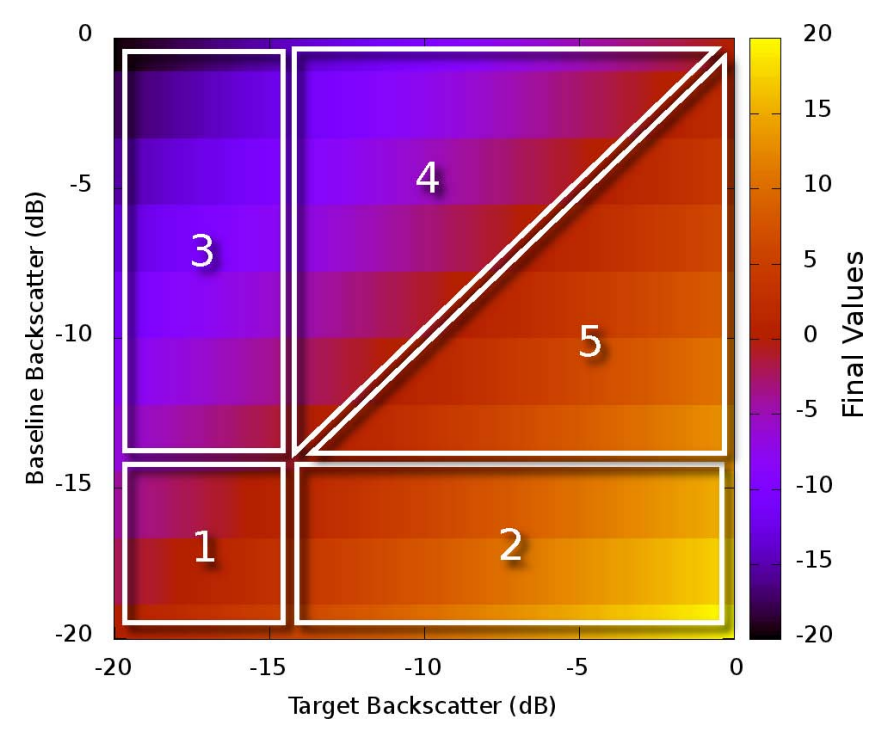

Fig. 3. Key map to describe range of $\Delta \sigma^{0}$ values derived from image differencing process.

\subsection{Expected values}

The range of values encountered in the resultant $\Delta \sigma^{0}$ image are represented graphically in Fig. 3, and may be categorised as follows:

1. Areas with values common to both the target and the baseline image are shown in red (values close to zero), and include permanent water and desert, shown in Box 1, together with all other unchanged values between Boxes 4 and 5.

2. Would occur where water were present in the baseline image and not in the target image (which is unexpected). Such values are far more likely to represent the surface of desert or very dry radar-dark soils becoming wet, which greatly increases backscatter (Robinson et al., 2006). These values can also represent the occurrence of Bragg Resonance due to wind effects on permanent water (Schaber et al., 1997).

3. Flooding. Mid-high values in the baseline image have become mid-low.

4. These have values below the threshold which may therefore be rightly or wrongly classified as flood water. It is with the intent to capture such errors that the regiongrowing algorithm, making spacial association relevant to the classification decision process, is adopted here.

5. Mid-high baseline values which undergo a small-large increase in backscatter values between the baseline and target images. Again, this can represent a dry surface becoming wet, but could also encompass open flood waters where conditions are right for wind-induced Bragg resonance to return a high backscatter signal. 
In the image differencing process, permanent water bodies, which are common to the baseline and target images, are removed. However, where water bodies are permanent and semi-permanent, their extents are easily mapped and overlain if required. We are interested here in mapping inundation outside of the current river coarse. The filling-in of permanent water after the flood classification and prior to testing would increase accuracy, but the results here are left as they are, with such limitations remaining exposed. Part of the reason for this is that the flood dynamics of the Pakistani rivers are complex, punctuated by sudden effects such as the breaching of the many levees which regulate their flow, and we therefore prefer in this instance to make no assumptions as to any possible deviations to the normal channel flow.

\section{Method}

\subsection{Data acquisition}

Data was acquired systematically via download from ESA's Kiruna and ESRIN ground stations, made available in a twoweek moving window through the Category 1 Fast Track Registration agreement.

\subsection{Coverage}

Area and frequency of cover of the region of interest was compared with MODIS Aqua and Terra data. In order to test comparative coverage, a mask was created by buffering the Indus river by $50 \mathrm{~km}$. For each day of August, the sum of pixels covered by GM data for that day were recorded along with the number of cloud-free pixels contained within the MODIS Terra and Aqua images, as a percentage of the total pixels for the masked region.

\subsection{Image preprocessing}

Incidence angles $(\theta)$, slant-range times (SRT) and geographical coordinates are provided within the raw GM data file, corresponding to tie points that form a grid with a spacing of 80-85 pixels across the image. Interpolation of $\theta$ and SRT was carried out first across the swath, and then the azimuth direction, to obtain values for each pixel. Terrain correction was also carried out in the frame of reference of the raw data file, due to the fact that columns and rows run parallel to the azimuth and swath respectively, making the geometry involved in the calculation much simpler. For this purpose, SRTM 7.5 arc-second Digital Elevation Model (DEM) data (Reuter et al., 2007; Jarvis et al., 2008) were projected into the local $\mathrm{x}-\mathrm{y}$ coordinate system. The incidence angles $\theta$ and the DEM were then used to calculate local incidence angles $(\alpha)$ for each pixel. Both the orthorectified Digital Number (DN) and $\alpha$ surfaces were then transformed to geographic coordinates by third order polynomial transformation.

\subsection{Image differencing}

For each target image acquired over the study area, a matching image from the same orbit track was chosen as a baseline, being the latest available image covering all of the azimuth extent of the target and occurring prior to the commencement of the flood event. Details of the data used are shown in Table 1. The raw data files were registered in a database, at which time tie point data, including coordinates, incidence angles and slant-range times were extracted.

\subsection{Baseline datasets from MODIS}

MODIS data were chosen from the results of the cloud-cover study described in Sect. 4.2, for three dates, with which to establish GM data classification thresholds and by which to gauge the accuracy of the classification process.

\subsection{Thresholding and classification}

In order to obtain a binary map of the inundated regions, a region-growing function provided as part of the GRASS GIS package (GRASS Development Team, 2009) was used. The r.lake function is primarily intended to fill a lake to a target water level from a given start point, or seed. This starting point can be a set of coordinates, or a raster map in which the seed points are represented by non-null values. The function will grow a region, starting at the seed points, until a specified water level is reached, as determined by a given DEM. In our case, the seed was a rasterised line-type shape file of Pakistan's river channels, the "DEM" was the $\Delta \sigma^{0}$ image, and the "water level" was set to the various thresholds tested. This method allows the use of a threshold value that is well inside the standard deviation of values for non-flooded areas, with the provision that the selected pixels are adjacent to other selected pixels as grown from the river channels. In order to try to mitigate errors of commission on the outskirts of the selected regions, a $3 \times 3$ modal neighbourhood filter was then applied to the binary classification.

MODIS band 6 data, representing Short Wave Infra-Red (SWIR) radiation $(\lambda=1628-1652 \mathrm{~nm})$, were used to map flooding and to establish thresholds to use with the radar images. Light in this short-wave infra-red waveband is absorbed by all but the most turbid water, and is therefore often used to map water (e.g. Ordoyne and Friedl, 2008; Dheeravath et al., 2010). Whilst MODIS reflectance bands provided by USGS attempt to achieve surface reflectance values, it is the case that attenuators such as thin cloud, that vary from image to image, preclude the use of a single absolute threshold applied to MODIS data in order to establish the benchmark. Figure 4 shows the density plot of MODIS Band 6 reflectance values over the flooded region from two images, taken two days apart. There is a clear full-range displacement of reflectance values of $0.03-0.05$. 
Table 1. GM Data used in this study. The Baseline Cycle refers to the orbit cycle corresponding to the deducted baseline data.

\begin{tabular}{|c|c|c|c|c|}
\hline & Date & $\begin{array}{l}\text { Orbit } \\
\text { cycle }\end{array}$ & $\begin{array}{l}\text { Orbit } \\
\text { track }\end{array}$ & $\begin{array}{r}\text { Baseline } \\
\text { cycle }\end{array}$ \\
\hline 1 & 1 April 2010 & 88 & 134 & - \\
\hline 2 & 17 April 2010 & 88 & 363 & - \\
\hline 3 & 13 Маy 2010 & 89 & 234 & - \\
\hline 4 & 16 May 2010 & 89 & 277 & - \\
\hline 5 & 26 May 2010 & 89 & 420 & - \\
\hline 6 & 1 June 2010 & 90 & 5 & - \\
\hline 7 & 6 June 2010 & 90 & 84 & - \\
\hline 8 & 7 June 2010 & 90 & 91 & - \\
\hline 9 & 12 June 2010 & 90 & 170 & - \\
\hline 10 & 15 June 2010 & 90 & 213 & - \\
\hline 11 & 17 June 2010 & 90 & 234 & 89 \\
\hline 12 & 19 June 2010 & 90 & 270 & - \\
\hline 13 & 20 June 2010 & 90 & 277 & 89 \\
\hline 14 & 22 June 2010 & 90 & 313 & - \\
\hline 15 & 23 June 2010 & 90 & 320 & - \\
\hline 16 & 28 June 2010 & 90 & 399 & - \\
\hline 17 & 1 July 2010 & 90 & 442 & - \\
\hline 18 & 3 July 2010 & 90 & 463 & - \\
\hline 19 & 4 July 2010 & 90 & 485 & - \\
\hline 20 & 5 July 2010 & 90 & 499 & - \\
\hline 21 & 9 July 2010 & 91 & 48 & - \\
\hline 22 & 11 July 2010 & 91 & 84 & 90 \\
\hline 23 & 12 July 2010 & 91 & 91 & 90 \\
\hline 24 & 15 July 2010 & 91 & 134 & 88 \\
\hline 25 & 17 July 2010 & 91 & 170 & 90 \\
\hline 26 & 22 July 2010 & 91 & 234 & 89 \\
\hline 27 & 24 July 2010 & 91 & 270 & 90 \\
\hline 28 & 25 July 2010 & 91 & 277 & 89 \\
\hline 29 & 27 July 2010 & 91 & 313 & 90 \\
\hline 30 & 28 July 2010 & 91 & 320 & 90 \\
\hline 31 & 31 July 2010 & 91 & 363 & 88 \\
\hline 32 & 2 August 2010 & 91 & 399 & 90 \\
\hline 33 & 4 August 2010 & 91 & 420 & 89 \\
\hline 34 & 5 August 2010 & 91 & 442 & 90 \\
\hline 35 & 7 August 2010 & 91 & 463 & 90 \\
\hline 36 & 8 August 2010 & 91 & 485 & 90 \\
\hline 37 & 9 August 2010 & 91 & 499 & 90 \\
\hline 38 & 10 August 2010 & 92 & 5 & 90 \\
\hline 39 & 13 August 2010 & 92 & 48 & 91 \\
\hline 40 & 15 August 2010 & 92 & 84 & 90 \\
\hline 41 & 16 August 2010 & 92 & 91 & 90 \\
\hline 42 & 19 August 2010 & 92 & 134 & 88 \\
\hline 43 & 21 August 2010 & 92 & 170 & 90 \\
\hline 44 & 24 August 2010 & 92 & 213 & 90 \\
\hline 45 & 26 August 2010 & 92 & 234 & 89 \\
\hline 46 & 28 August 2010 & 92 & 270 & 90 \\
\hline 47 & 29 August 2010 & 92 & 277 & 89 \\
\hline 48 & 31 August 2010 & 92 & 313 & 90 \\
\hline 49 & 1 September 2010 & 92 & 320 & 90 \\
\hline 50 & 4 September 2010 & 92 & 363 & 88 \\
\hline 51 & 6 September 2010 & 92 & 399 & 90 \\
\hline 52 & 8 September 2010 & 92 & 420 & 89 \\
\hline 53 & 9 September 2010 & 92 & 442 & 90 \\
\hline 54 & 11 September 2010 & 92 & 463 & 90 \\
\hline 55 & 12 September 2010 & 92 & 485 & 90 \\
\hline 56 & 13 September 2010 & 92 & 499 & 90 \\
\hline 57 & 14 September 2010 & 93 & 5 & 90 \\
\hline 58 & 17 September 2010 & 93 & 48 & 91 \\
\hline 59 & 20 September 2010 & 93 & 91 & 90 \\
\hline 60 & 25 September 2010 & 93 & 170 & 90 \\
\hline 61 & 28 September 2010 & 93 & 213 & 90 \\
\hline 62 & 5 October 2010 & 93 & 313 & 90 \\
\hline 63 & 6 October 2010 & 93 & 320 & 90 \\
\hline 64 & 9 October 2010 & 93 & 363 & 88 \\
\hline 65 & 14 October 2010 & 93 & 442 & 90 \\
\hline 66 & 17 October 2010 & 93 & 485 & 90 \\
\hline
\end{tabular}

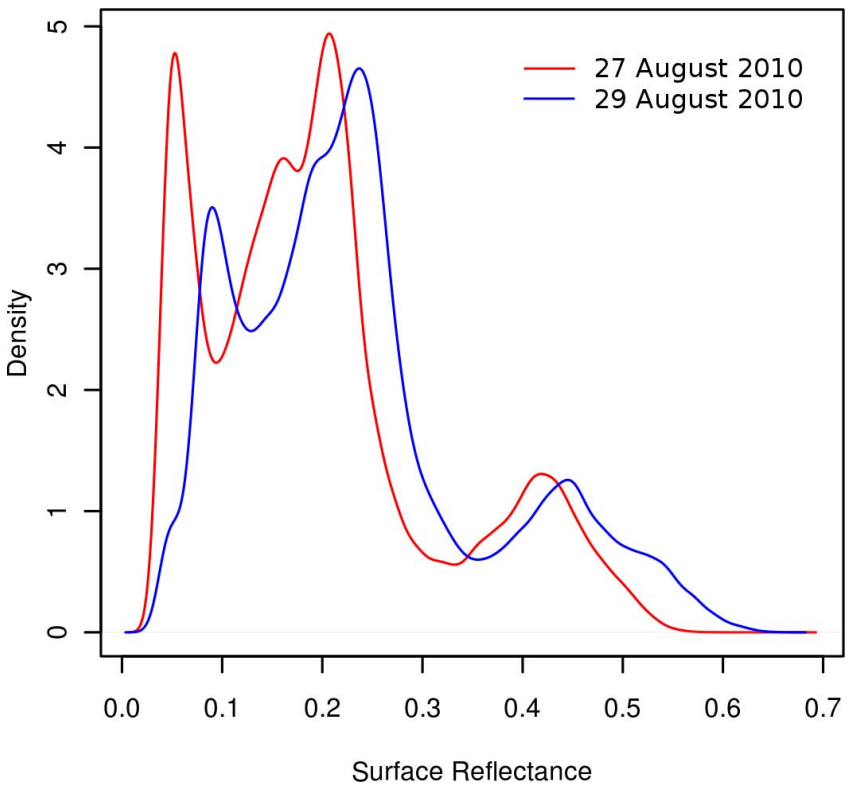

Fig. 4. Density plot of MODIS Band 6 reflectance values over the flooded region on 27 and 29 August 2010. The peaks at reflectance values of 0.05 and 0.1 represent water, as is seen later in the kappa analyses.

To account for this uncertainty, a bivariate sensitivity analysis was carried out, matching conformance of a range of radar backscatter thresholds in the radar images against a range of thresholds in the contemporaneous MODIS images. A peak in cross-correlation outside of the extreme threshold values (which would classify the whole image as flooded or non-flooded) would only likely represent common optimal flooded/non-flooded thresholds, as beyond the low signal response to water common to SWIR and radar data, the characteristic responses of each of the wavebands are largely independent. In order to gauge the performance of classifications under varied thresholds, it is insufficient to simply determine the percentage of coincidence of allocated classes, as this gives a distorted result. If, for example, a flooded area comprises $5 \%$ of the region under study, then a classification omitting all the flooding would, with such a method of assessment, be $95 \%$ correct. For this reason, Cohen's kappa statistic is often used as a "coefficient of agreement" between two classification processes (Cohen, 1960; Tolpekin et al., 2009; Foody, 2006; Hunt et al., 2010). The kappa statistic $\kappa$ is calculated as

$\kappa=\frac{p_{0}-p_{\mathrm{c}}}{1-p_{\mathrm{c}}}$

where $p_{0}$ is the proportion of pixels in which agreement is observed and $p_{\mathrm{c}}$ is the theoretical proportion expected by chance selection (Cohen, 1960). It is the latter parameter which is perceived in certain instances to be problematic, as the observed proportion of allocation to each class is used as a basis to calculate random expectation (in effect, assuming 
that the decision process will always allocate the correct proportion of pixels to each class, whether the specific allocations are correct or not). This is not considered an issue in our case. Firstly, the assumption of proportion is observed to be approximately correct. Secondly, we are, while in pursuit of an optimal threshold, seeking a relative measure of classification accuracy rather than an absolute one.

Where good clear MODIS data were available during the flood event, $\kappa$ was calculated for a matrix of classifications made with SWIR reflectance upper thresholds ranging between 0.05 and 0.25 , and GM (difference image) $\Delta \sigma^{0}$ upper thresholds ranging between -10 and $0 \mathrm{~dB}$. From this, the optimal backscatter thresholds could be observed, together with their sensitivity and inter-image variability. A comparison was made using the single target GM image, with a groundrange projected backscatter $(\gamma)$ upper threshold range between -20 and $0 \mathrm{~dB}$. A threshold to be used where MODIS data were unavailable was decided in this way, and its suitability assessed on a further series of $\kappa$ analyses on another date for which MODIS data were available.

\section{Results}

\subsection{Coverage}

During the 98 days between 11 July and 17 October 2010, the average repeat coverage period by GM data over the region studied was around 9 days (see Fig. 5). Though this would be insufficient for a complete time series of the flood dynamics, it can feasibly serve to fill the gaps in information gained from optical sensors such as MODIS caused by the presence of cloud cover. Figure 6 shows a comparison of percentage of the full flood extent captured independently by MODIS Terra, MODIS Aqua and GM data, for each day of August 2010. Cloud cover limited the use of MODIS data through the first week of August, during the build-up of flood waters north of Sukkur, whilst there were sufficient GM data to build a picture of the flood extents at this time. Much of the rain that caused the floods in Pakistan fell on the ranges to the north, and as such, there were significant periods free of cloud further down stream where most of the catastrophic flooding occurred, and so in this respect, as a "dry flood", this event enjoyed better coverage than most similar events with optical data, and in many other flood events, it may be reasonably assumed that the difference in availability of data could be far greater.

\subsection{Image differencing}

It can be seen from the probability density functions shown in Fig. 7 that attempts to map flooding using a simple threshold would result in large errors of commission and omission, due to the range of overlap of values. In the non-flooded areas, as we have chosen a region close to the known flooding, the slight rise in average backscatter value may be due in part

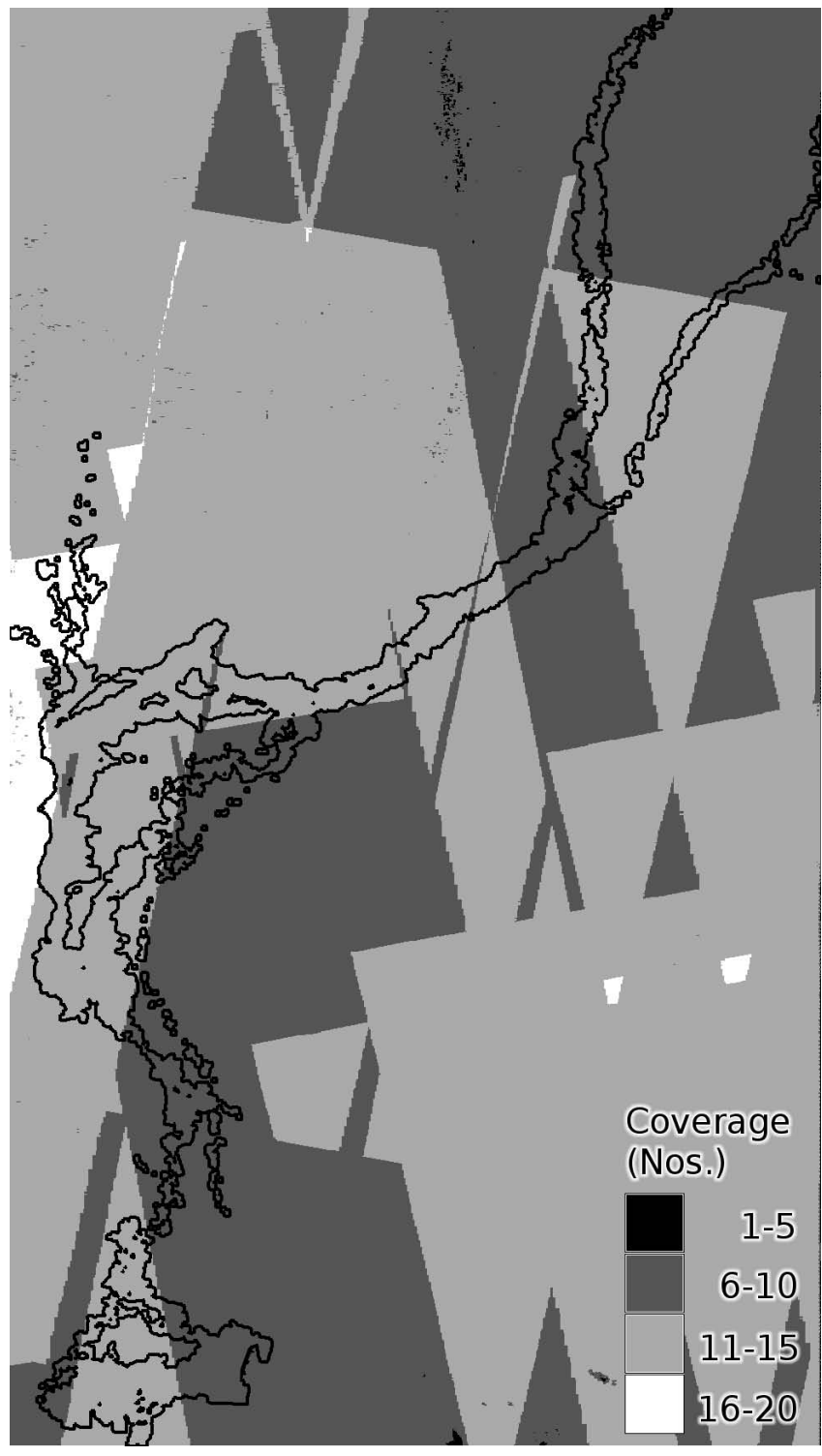

Fig. 5. Count of frequency of cover by GM data over the 98 day study period. The black outlines represents the maximum flood extent.

to increased surface soil moisture (Pathe et al., 2009) in the vicinity of the flood and possibly from dihedral scattering from vegetation emergent from flood waters at the boundary of the flooded class regions (Hess et al., 2003). In addition to native vegetation close to the main river channel, wheat, cotton, onion, sunflower, rice, pulses and dates are all grown in the region (Ashraf and Majeed, 2006). The large standard deviation of $\Delta \sigma^{0}$ values in the non-flooded regions can be explained by a couple of factors. Firstly the propensity of radar data to contain noise, most of which is speckle. This is characterised by high and low valued pixels whose values represent interference arising from the use of a coherent electromagnetic radiation source, rather than having anything to 


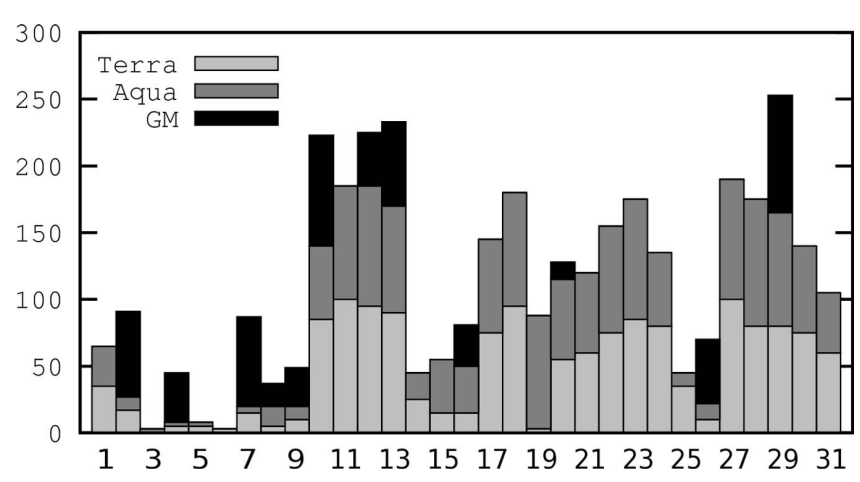

Fig. 6. Percentage of full flood extent covered on each day of $\mathrm{Au}-$ gust 2010 by MODIS Terra, MODIS Aqua and GM data.

do with the target. Speckle can lead to sharp differences in values between any two radar images. Secondly, variations in the immediate recent rainfall history can cause large differences in backscatter value. Not only moist soil, but also wet vegetation tends to give a high backscatter response at C-band (e.g. Ulaby et al., 1982). A drop in radar value in non-flooded areas can be seen where smooth specular reflecting alluvial sediments, for example, dry out. Low backscatter also occurs where the signal is absorbed/attenuated by very dry sand (Robinson et al., 2006; Schaber et al., 1997), though such a fall from relatively wet to very dry conditions necessary to produce a low $\Delta \sigma^{0}$ value are unlikely to have occurred so close to the main channel.

The distribution of $\Delta \sigma^{0}$ values in the flooded region is perhaps best explained in terms of what may be observed in Fig. 8. The images centre on the segment of the Indus river running between Sukkur and Dadu, where its course changes from a south-west to a south-east direction. The image on the left shows radar backscatter values acquired on $20 \mathrm{Au}$ gust 2010. The image on the right shows the same values, with those of a previous cycle deducted. The regions labelled $\mathrm{D}$ and $\mathrm{F}$ represent sections of the river characterised by a large flood channel superimposed with the meandering and anabranching main Indus channel (see Fig. 9). At the time of acquisition, this large channel was completely flooded, and appears as radar dark in the first image. However, due to the fact that alluvial sediment can also act as a specular reflector in the same way as water, much of the D region is punctuated with mid-range value pixels in the difference image, and region $\mathrm{F}$ is all but indistinguishable from non-flooded land. The large area at A with low backscatter values in the first image shows that part of the lowlands which protrudes into the Sulaiman mountains of Balochistan, comprising mainly the districts of Bolan and Sibi. This region is normally dry, with an annual rainfall of $200-250 \mathrm{~mm}$. The low backscatter is considered to be the result of attenuation and absorption of the signal, rather than of specular reflection. The low backscatter values are clearly offset in the difference image, leaving only those low values representing

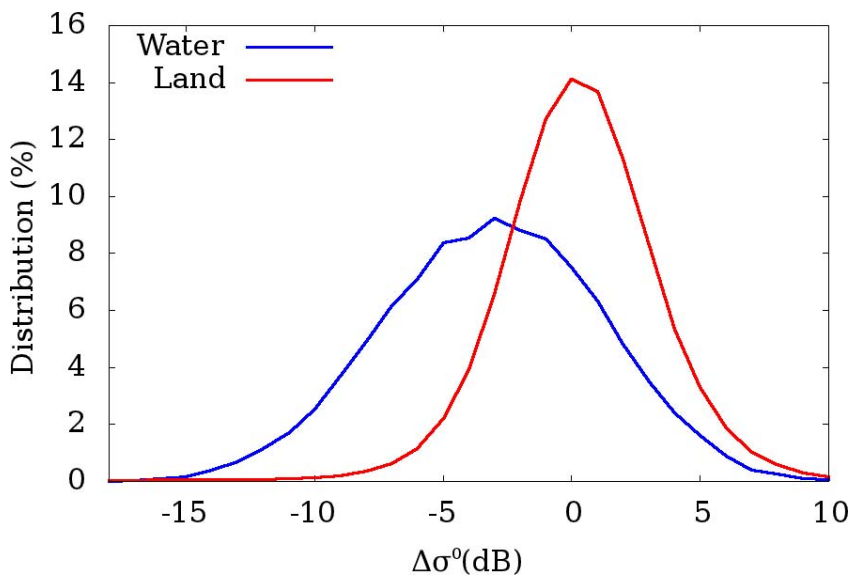

Fig. 7. Probability density functions for $\Delta \sigma^{0}$ for water and land over the flooded region on 29 August 2010, as determined by classification using MODIS SWIR Reflectance Threshold of 0.13 .

the rivers that run west below A and then south towards Lake Manchar below B. Similarly, the dark region in the first image at $\mathrm{C}$ is at the western edge of the Thar Desert. The bright strip running north-south immediately to the right of $\mathrm{C}$ shows the relatively high backscatter from the vegetation bordering the Nara Canal and its irrigated hinterland. As with A, the response of both the irrigated strip and the desert are common to the consecutive orbit cycles, and hence do not appear in the difference image.

\subsection{Thresholding and classification}

A comparison of value profiles of $\Delta \sigma^{0}$ and MODIS Band 6 across a section of the flooded Indus, as at 10 August 2010, is shown in Fig. 10. It can be seen that, at this scale, the choice of threshold of Band 6 to classify water is not particularly sensitive between around 0.2 and 0.15 units, where the profile crosses the flooded area, with relatively few pixels taking intermediate values. There is little doubt that where SWIR reflectance values fall close to zero on all legs, there is open water. In these areas along legs 1, 2 and 3, the corresponding $\Delta \sigma^{0}$ values fall below $-2 \mathrm{~dB}$, corresponding to a fall in backscatter values caused by increased specular reflection, due to the increased presence of water. Along legs 4 and 5, however, there are large fluctuations of $\Delta \sigma^{0}$ values. This is mainly due to the fact that, as mentioned before, the alluvial sediment can also act as a specular reflector in the same way as water, thus the dry baseline low pixel values are offset from the target image, producing mid-range difference values. Areas where a slight rise in SWIR reflectance coincides with a sharp rise in $\Delta \sigma^{0}$ (such as at $40 \mathrm{~km}$ and $120 \mathrm{~km}$ on the $\mathrm{x}$-axis) are believed to represent partial inundation with emergent vegetation, the high $\Delta \sigma^{0}$ values being the result of dihedral scatter. 


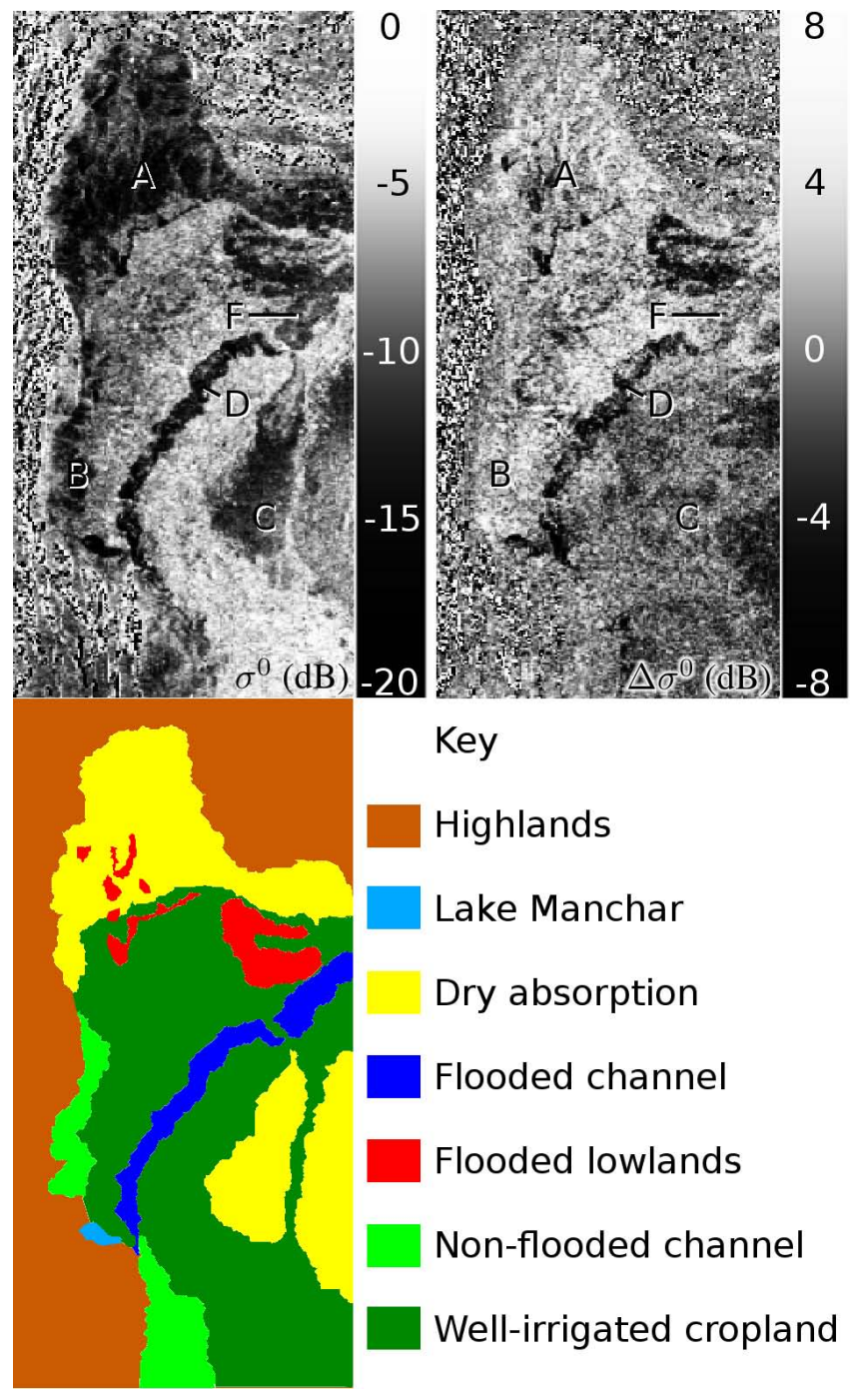

Fig. 8. The region between Jacobabad and Nawabshah in mid August 2010. The image on the left shows backscatter values in decibels. Smooth open water is commonly represented by values of around $-16 \mathrm{~dB}$ or below. The image on the right shows the same data, with the values from the previous cycle along the same orbit track having been deducted. A better understanding of the true extent of flooding can be discerned by a difference of around $-4 \mathrm{~dB}$ in this image.

These profiles demonstrate the volatility of $\Delta \sigma^{0}$ values, especially in those areas that show a low backscatter response under non-flooded conditions, as discussed above. It was found that the choice of a simple $\Delta \sigma^{0}$ threshold to suit conditions in the main river channel would result in many regions mapped incorrectly as flooding in areas well away from the river channels. For this reason it was decided to make contiguousness with other flooded pixels adjacent to the river channels a condition of the flood class, in addition to the satisfaction of the $\Delta \sigma^{0}$ threshold. Therefore flooded regions were mapped by growing contiguous areas that satisfied the

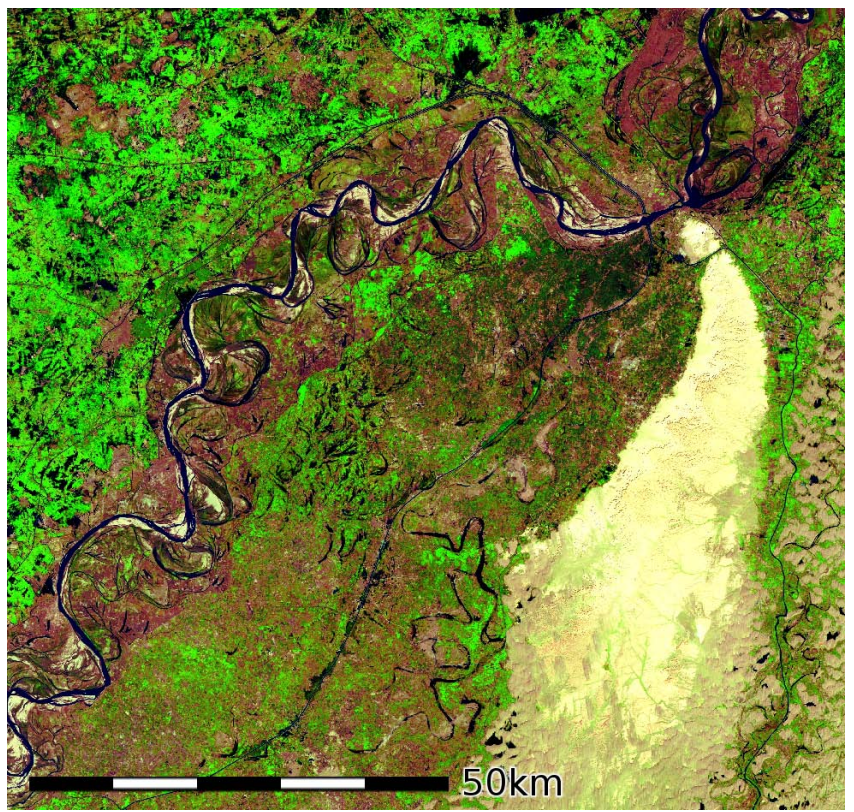

Fig. 9. Landsat composite colour image of the Indus and its floodplain southwest of Sukkur. The Nara canal is seen running northsouth to the right of the image.

threshold criterion from pixels at the centre of the river channel outwards, using the technique described in Sect. 4.6.

\subsubsection{Bivariate sensitivity analysis to determine threshold}

$\kappa$ statistic values calculated in the sensitivity analysis described in Sect. 4.6 are shown in Figs. 11, 12 and 13. It can be seen that, while the optimal SWIR reflectance threshold varies between the dates, the optimal $\Delta \sigma^{0}$ threshold of around $-2 \mathrm{~dB}$ is common to the three instances. The reasons for the differences in the MODIS thresholds was discussed in Sect. 4.6 and the difference between the optimal reflectance thresholds of 0.07 and 0.11 on 27 and 29 August respectively are manifest in the shift in distribution of values between the two MODIS images that was shown in Fig. 4.

Figure 14 shows flood extent estimates from MODIS (top), the single contemporaneous GM image (centre) and the GM Difference image (bottom), each using thresholds optimized from the process described above.

With the single image in the centre, there are two processes resulting in the low backscatter response. To the north-west of the dashed line, the low response is dominated by specular reflection from the surface of flood waters. To the south-east of the dashed line, the low backscatter response is caused by absorption in desert sands. The wrongly classified desert area is eliminated in the third image, as this low response from the desert areas is common to both the target image and its baseline partner, and is therefore subtracted out. 


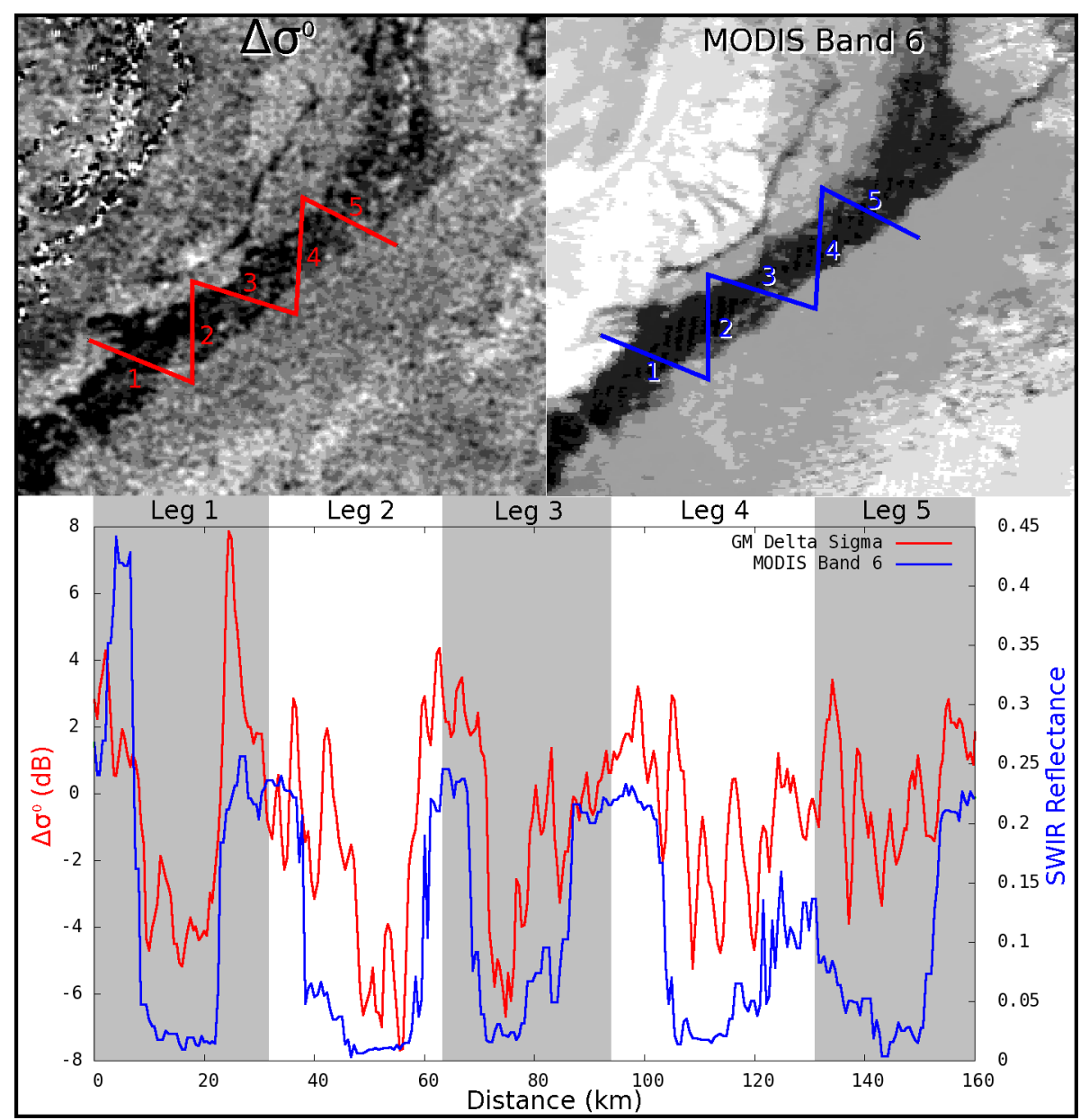

Fig. 10. Comparison of value profiles of $\Delta \sigma^{0}$ (top-left image, red profile) and MODIS Band 6 (1628-1652 nm) (top-right image, blue profile) from a section of the flooded Indus on 10 August 2010.

When comparing the MODIS (top) image with the Difference image (bottom), it can be seen that whilst the boundaries of the flood are well defined, areas of permanent water or radar-dark flood plain regions are also eliminated. In the central image derived from the single GM data set, such areas which do fall within the flooded region are more completely defined. With a priori knowledge of terrain and environmental conditions, one can mask out desert areas and achieve a more accurate classification using the single image. Masking must be very precise, however, as some absorption areas can lie extremely close to the flooded region, as can be seen from the area encircled in red in the middle image. Assuming sufficient information is available within the time frame allowed, the higher accuracy which may be achieved by such masking is demonstrated in Fig. 15, where a $\kappa$ value of 0.7 is achieved. Note that the precedence of MODIS SWIR thresholds matches that seen in Fig. 12, as expected.

Where a fast indicator of the extent of flooding through otherwise dry land is urgently required, we propose that the image differencing technique offers a reasonably stable means to identify those extents between periods where optical data are unavailable, enabling a broad scale view of the flood dynamics with a better temporal resolution than could otherwise be achieved.

\subsection{Inundation dynamics}

Figure 16 shows instances from the resultant time series of binary flood maps. The first two images show the build up of the upper reaches of the Indus. By 7 August, the Chenab has flooded and the main flood has reached Kashmore. The image at 12 August shows the situation following the breaching of a bund at Thori in Kashmore. By 20 August the flood has reached the Hyderabad district. The 29 August image shows the results of two significant breaches, one at Sukkur, allowing the flood to split and inundate the Jacobabad region to the north of the Indus, and another at Sarjani to the south, where part of a dyke collapsed on 26 August. This resulted in the extensive flooding in the south which is evident on 11 September. The final two images, set three weeks apart, 


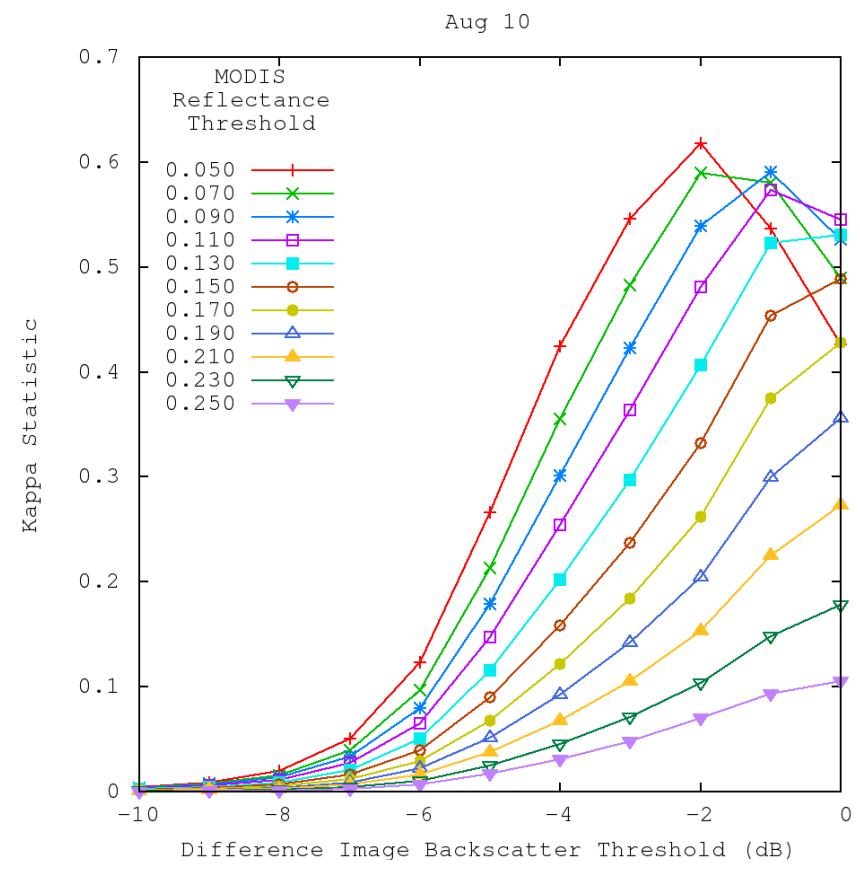

Fig. 11. $\kappa$ statistic calculated for individual classifications of flooding on 10 August 2010, based upon $\Delta \sigma^{0}$ thresholds ranging from -10 to $0 \mathrm{~dB}$. The series represents corresponding MODIS Band 6 reflectance thresholds used in the reference image, ranging from 0.05 to 0.25 .

show the flooded region covering over $7000 \mathrm{~km}^{2}$ between Jacobabad and the Manchar Lake in Dadu, which remained for many weeks. Beyond 20 October 2010, there followed a period in which the Envisat satellite underwent a scheduled program change, during which time GM data was unavailable.

Figure 17 shows the duration of flooding over the full extents, up to 17 October 2010, as derived from the GM data. Many regions remained inundated for several weeks, the greatest duration being observed in the area around Jacobabad described above. The greatest flood duration shown at 97 days represents the enlarged Lake Manchar to the southwest of this region.

An idea of the propagation speed of flood waves can be gained from Fig. 18, which shows the distance along the Indus river channel of the head of the main flood, and the receding tail end. The initial advance covered some $500 \mathrm{~km}$ in 5 days (about $4 \mathrm{~km}$ per hour), with the flood reaching the southern extents towards the end of the first week in September. The greatest length of flooding occurs where the recession curve is flattest at around 21 August. The recession rate is seen to increase at the end of August, following the bund breaches at Sukkur and Sarjani, flattening off once more in early September, when the front of the flooding is seen to retreat back to localised areas.

Figure 19 shows the flooded area over the time series, derived from the combination of GM and MODIS data. The lower curve shows only the flooding around the main Indus

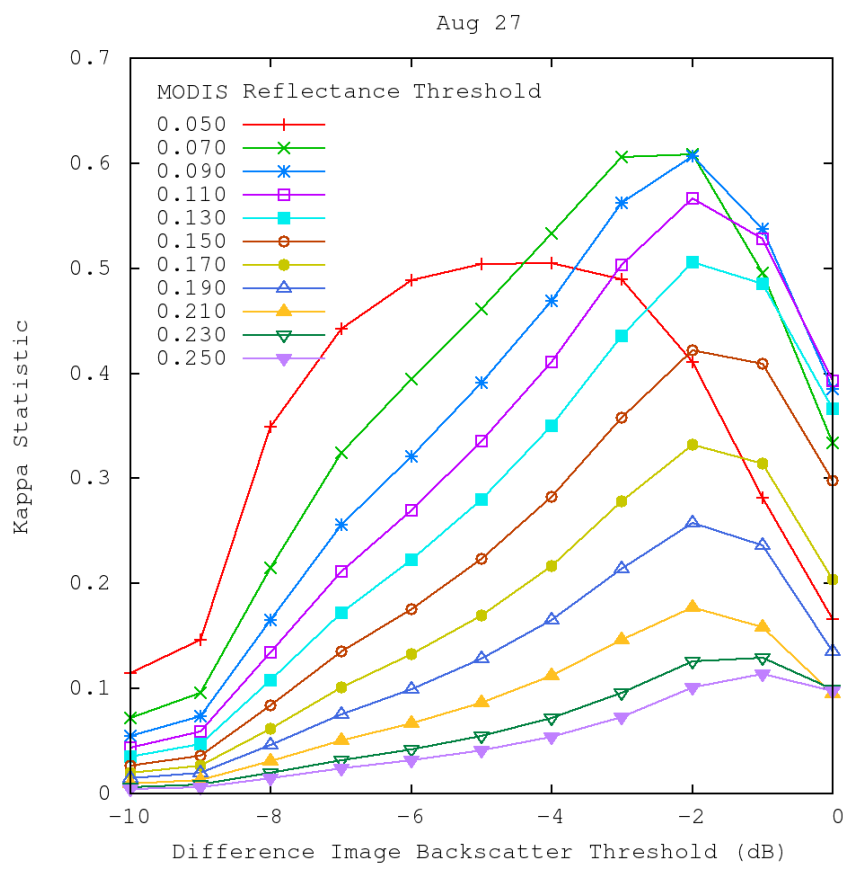

Fig. 12. $\kappa$ statistic calculated for individual classifications of flooding on 27 August 2010, based upon $\Delta \sigma^{0}$ thresholds ranging from -10 to $0 \mathrm{~dB}$. The series represents corresponding MODIS Band 6 reflectance thresholds used in the reference image, ranging from 0.05 to 0.25 .

Channel. The upper curve shows the total area, including the near-static flooding between Jacobabad and Dadu, which remained well into October 2010.

\subsection{Accuracy}

A measure of the classification accuracy of this method was known throughout from the $\kappa$ statistic values used to ascertain the optimal thresholds to use. The consequence of fixing a $\Delta \sigma^{0}$ threshold of $-2 \mathrm{~dB}$ based on the $\kappa$ tests done on 10 and 27 August was further tested on the classification done for 29 August, the results of which are tabulated in Table 2 and shown graphically in Fig. 20. The $\kappa$ statistics over the full range of MODIS Band 6 reflectance values and $\Delta \sigma^{0}$ values were also seen in Fig. 13.

The following factors are considered to be the main contributors to inaccuracy:

- As discussed in Sect. 5.2, much of the flooded region covers the immediate flood plain which ordinarily contains large meanders, anabranching and ox bow lakes. Low backscatter returns from these semi-permanent water bodies contribute to to a lower value in a larger area of the baseline image when averaged to a pixel size of $500 \mathrm{~m}$. This is offset from similar values in the target image, resulting in mid-range values, incorrectly interpreted as land. 


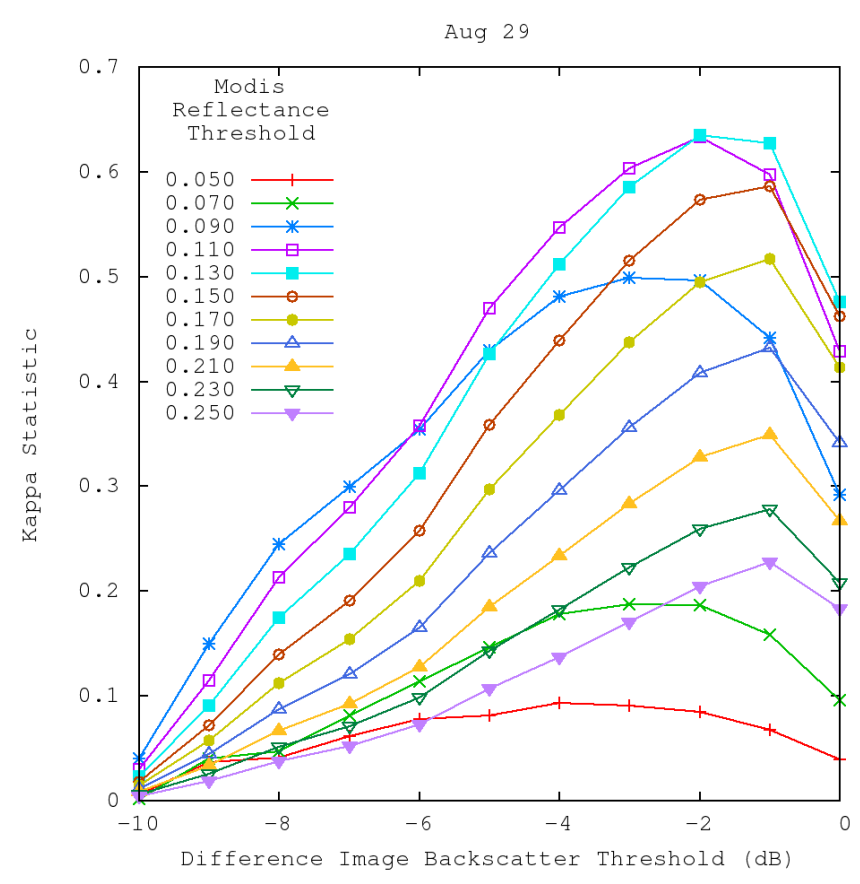

Fig. 13. $\kappa$ statistic calculated for individual classifications of flooding on 29 August 2010, based upon $\Delta \sigma^{0}$ thresholds ranging from -10 to $0 \mathrm{~dB}$. The series represents corresponding MODIS Band 6 reflectance thresholds used in the reference image, ranging from 0.05 to 0.25 .

- Semi-submerged vegetation can cause high backscatter values due to multihedral scattering as discussed, which, again, when averaged with low values from open water may return a mid-range value.

- Wind conditions may be such that Bragg Scattering occurs, causing relatively high return values. Determination of the extent of this effect would require detailed wind speed and direction data, which were not available for this period.

\section{Discussion}

\subsection{Natural disaster response}

For regions which face a high risk of flooding that may be ever increasing (Schiermeier, 2011), mitigating the impact of flooding can fall within two broad categories: planning and organisation based on predicted scenarios, and reactive response during and after an event. Action under the first of these requires an understanding of processes which govern the magnitude and extent of possible floods. Such an understanding cannot rely exclusively on historical data where land use and climate are changing, but must instead require predictive modelling.

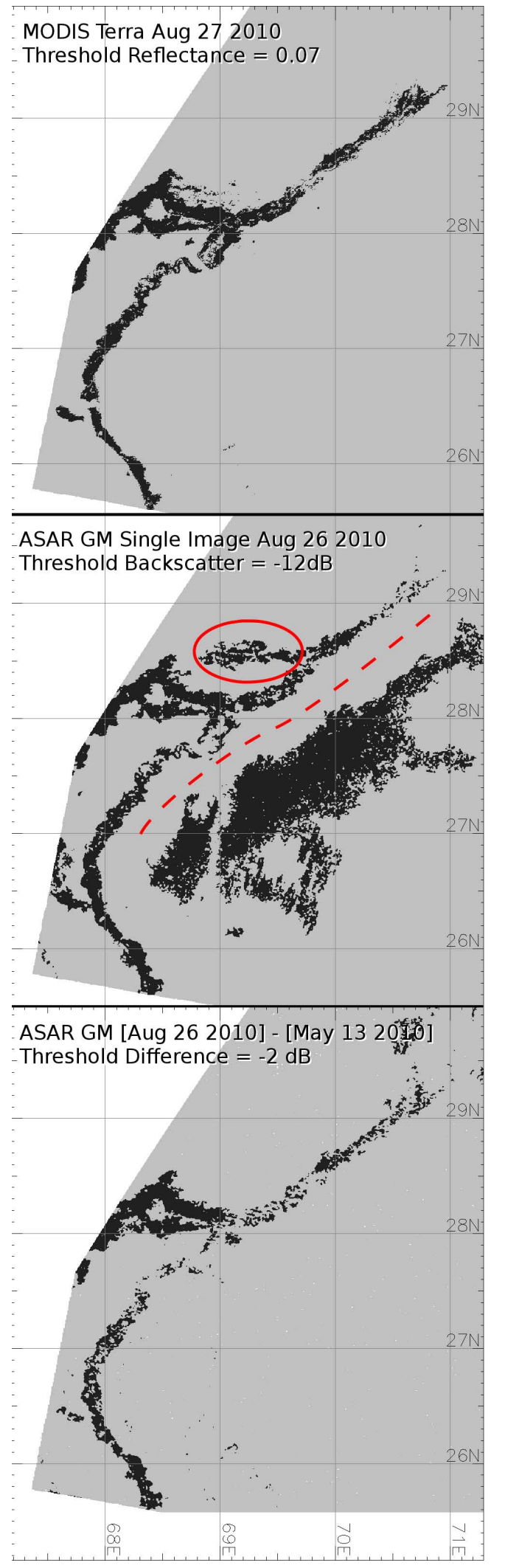

Fig. 14. Flood extent estimates from MODIS (top, $\kappa=1$ ), the single contemporaneous GM image (centre, $\kappa=0.3$ ) and the GM Difference image (bottom, $\kappa=0.6$ ), using optimised thresholds. 


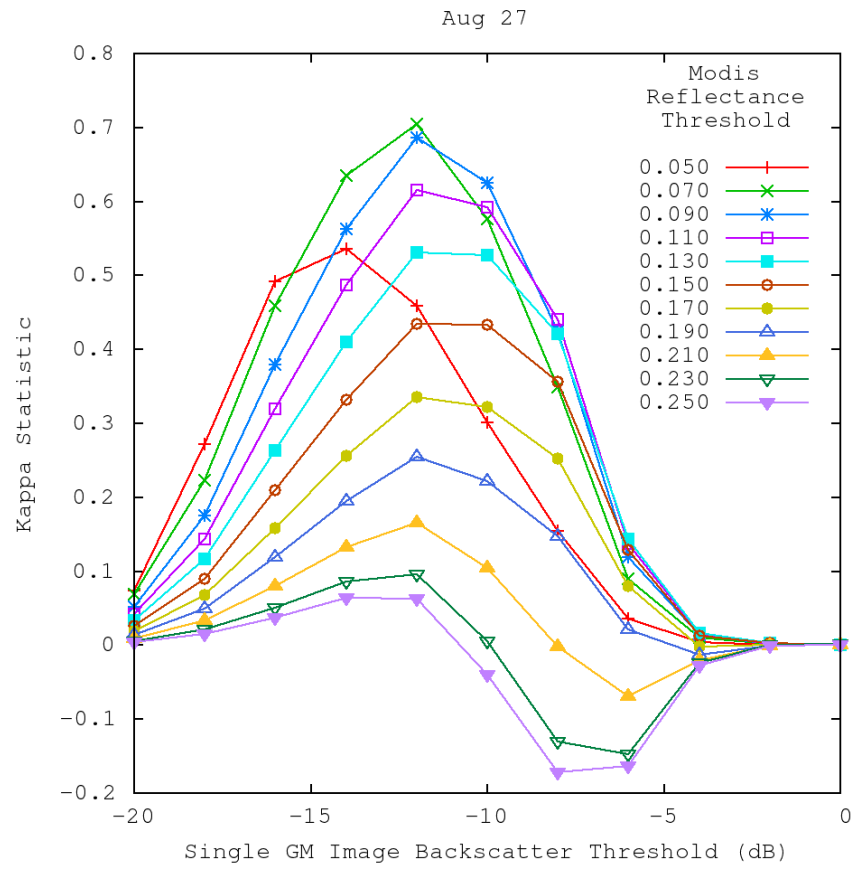

Fig. 15. $\kappa$ statistic calculated for individual classifications of flooding on 27 August 2010, based upon $\gamma$ thresholds ranging from -20 to $0 \mathrm{~dB}$, following precise masking of radar-dark dry land established from the image differencing process. The series represents corresponding MODIS Band 6 reflectance thresholds used in the reference image, ranging from 0.05 to 0.25 .

Remote sensing has played an increasingly important role in this process in recent years. The establishment of parameters in hydrological models have called upon, for example, leaf area index calculations or on surface water extents using data from optical sensors such as Landsat Thermal Mapper (Chen et al., 2004; Stisen et al., 2008; Milzow et al., 2009a) and have increasingly incorporated soil moisture values gained from Envisat ASAR in such modelling (Decharme et al., 2009; Liu et al., 2010; Saux-Picart et al., 2009). Radar-derived DEM's have been assessed and used in hydrological modelling widely (e.g. Ludwig and Schneider, 2006). More directly, hydraulic processes involved in flooding have been modelled to estimate flood magnitudes (Conesa-Garcia et al., 2010; Hostache et al., 2009) and to develop flood inundation models (Schumann et al., 2007). Coupled models using SAR data have been employed in the last few years to useful effect. Montanari et al. (2009) investigate the usefulness of SAR data to gauge flood extents and stage heights in deriving soil saturation values. Milzow et al. (2009b) seek to verify hydrological models by comparing simulated flood patterns with flood maps derived using AVHRR and ASAR data. Pauwels et al. (2009) calculate soil hydraulic conductivity values through a combination of SAR-based moisture maps and land surface modelling.
Table 2. Error matrix and $\kappa$ statistic for the flood map on 29 August 2010 when compared with MODIS flood classification.

\begin{tabular}{|c|c|c|c|c|c|}
\hline & \multicolumn{5}{|c|}{ MODIS } \\
\hline & Category & \multicolumn{2}{|c|}{ Flooded } & Non-Flooded & Row Sum \\
\hline$\Delta$ & Flooded & & 761 & 10464 & 45225 \\
\hline \multirow[t]{2}{*}{$\sigma^{0}$} & Non-Flooded & & 562 & 228902 & 247564 \\
\hline & Col Sum & & 423 & 239366 & 292789 \\
\hline \multicolumn{2}{|c|}{ Cats } & \multicolumn{2}{|c|}{$\%$ Commission } & $\%$ Omission & Est. $\kappa$ \\
\hline \multirow{2}{*}{\multicolumn{2}{|c|}{$\begin{array}{l}\text { Flooded } \\
\text { Non-Flooded }\end{array}$}} & \multirow{2}{*}{\multicolumn{2}{|c|}{$\begin{array}{r}23.1 \\
7.5\end{array}$}} & 34.9 & 0.71 \\
\hline & & & & 4.4 & 0.59 \\
\hline & & $\kappa$ & \multicolumn{2}{|c|}{$\kappa$ Variance } & \\
\hline & & \multicolumn{3}{|c|}{ 0.65 0.000004} & \\
\hline & Obs Correct & \multicolumn{2}{|c|}{ Total Obs } & \multicolumn{2}{|c|}{$\%$ Observed Correct } \\
\hline & 263663 & \multicolumn{2}{|c|}{292789} & \multicolumn{2}{|r|}{90.1} \\
\hline
\end{tabular}

Predictive modelling has significant limitations in certain instances. An example of this can be observed in the case of the floods in Pakistan. There are limitations to ascertaining water volumes for the modelling process in large areas of very low gradient, necessitating a spatially and radiometrically high resolution DEM (Sanyal and Lu, 2004). Further to this, the use of levees on a large and small scale is widespread throughout the floodplain, many of which are built "privately" and therefore remain unmapped ${ }^{3}$. In this case, therefore, the importance of flood mapping based on observation, increases. So too does the significance of data availability, speed of acquisition, spatial coverage and temporal resolution.

\subsection{Use and limitations of the GM data for flood mapping}

The swath width of GM data is $\sim 405 \mathrm{~km}$ and permits a synoptic assessment of large flood events at the basin scale. Capturing the onset of a flooding event as early as possible is critical for emergency response. ENVISAT ASAR GM was one of the few sensors capable of capturing the full extent of the flooding in Pakistan during the first week and a half (e.g. MODIS data were unavailable from 2 to 9 August 2010 due to high cloud cover). ENVISAT ASAR GM acquisition is not systematic but will depend on other modes being switched off. Hence the coverage of a particular region can be variable. Across Asia, we found from September 2009 to May 2011 an average of 2-3 weekly observations at a single location. Over the same period there were no GM data acquired over New Zealand and 8 per week in parts of North America. Average frequency of land coverage per week by GM data over this 600 day period is shown in Fig. 21. The

\footnotetext{
${ }^{3}$ see http://tribune.com.pk/story/219602/ private-dykes-on-public-land-may-lead-to-another-bout-of-floods/, for example
} 


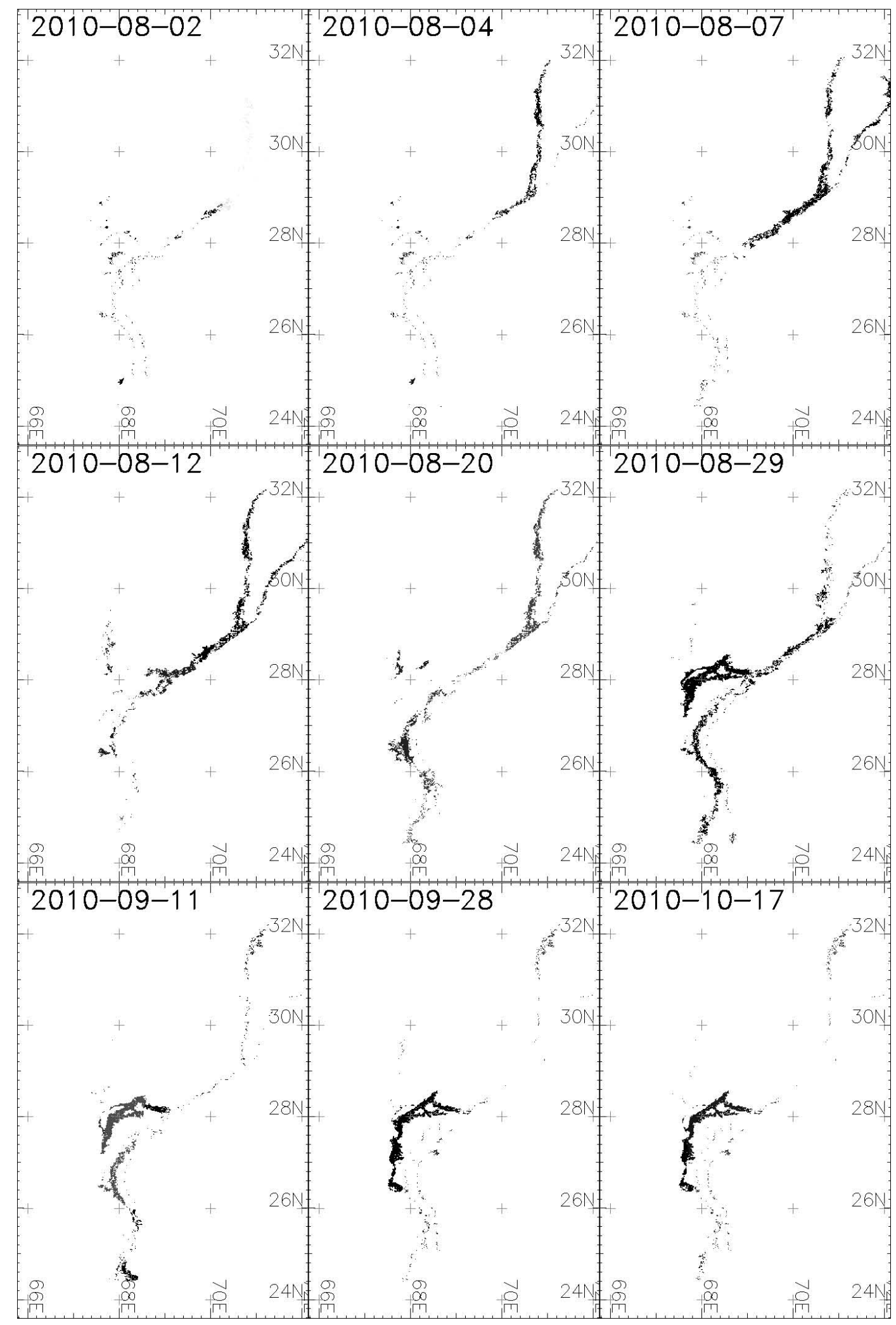

Fig. 16. Selected instances from the time series showing the build-up of flooding and much of its recession. Flooding is still evident in the third week of October 2010, at which time data temporarily ceased to be available, due to ESA's scheduled preparations for Envisat's project extension program. 


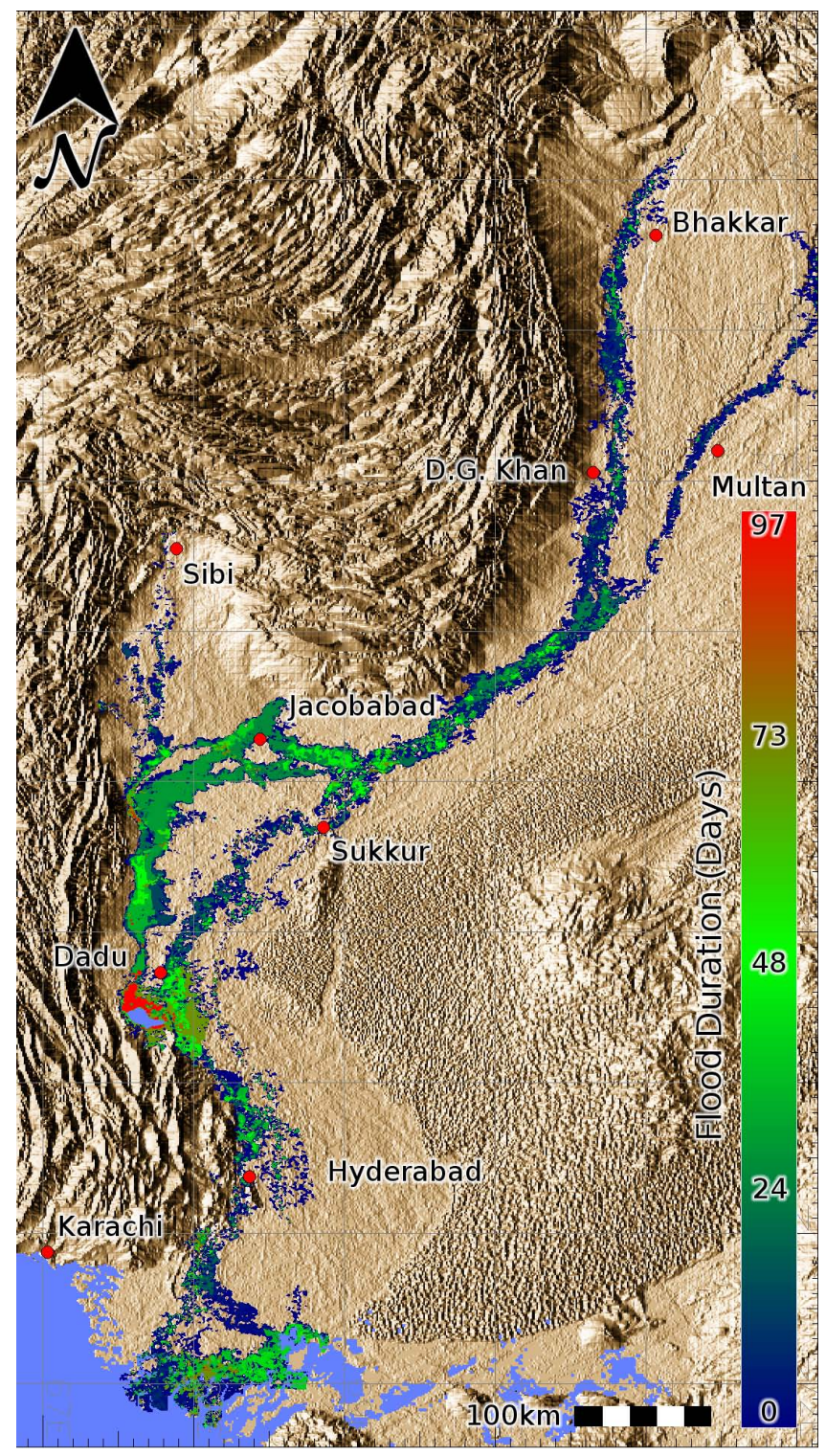

Fig. 17. Map showing the extent and duration of inundation surrounding the Indus and Chenab rivers as derived from satellite radar data acquired between July and October 2010.

temporal distribution is not evenly spread. Southeast Asia, for example, received virtually no coverage for the first four months of the study period.

In Pakistan, we found the coverage of the ENVISAT ASAR Global Mode data was adequate to capture the dynamics of the propagation of the 2010 flood across the entire Indus Basin (Figs. 5 and 6). However, a lower acquisition frequency from 17 August 2010 onwards only allows for partial coverage of the recession of the flood.

A major limitation of the ASAR GM mapping technique used here is that inundated area with emergent vegetation can be confused with land area of high soil moisture.

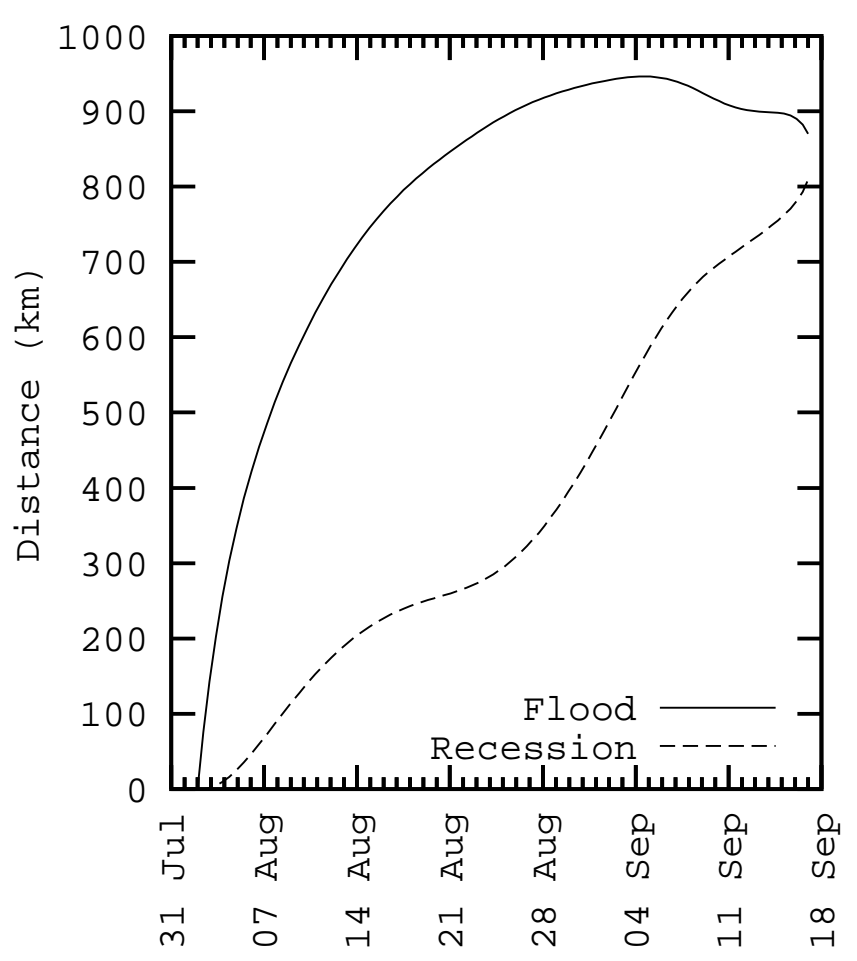

Fig. 18. Distance of the flood head and tail along the Indus channel from the foot of the northern ranges at $71^{\circ} \mathrm{N}, 32^{\circ} \mathrm{S}$.

Wind-induced waves can also generate a roughening of the water surface which increases the scattering of the radar signal due to Bragg resonance; a phenomenon that is more pronounced in C than L-band over inland water bodies (Alpers, 1985; Alsdorf et al., 2007). Finally, partial flooding inside a pixel can be a common feature at this scale (spatial resolution of $\sim 1 \mathrm{~km}$ ) especially along braided channels and will result in mixed pixels composed of land, water and flooded vegetation, which can return a wide range of signals.

The original mapping presented here was carried out in response to a request for a timely indication of the extent of flooding by a UN emergency response team when the event was in full throw, when expediency and simplicity competed with sophistication of technique as priorities. The methods lend themselves to seek greater accuracy by further analysis, building on thresholding and region-growing techniques by, for example, Yu and Clausi (2007); Matgen et al. (2011); Galland et al. (2009) and Silveira and Heleno (2009). Other successful segmentation methods for SAR images involving texture and shape (van der Werff and van der Meer, 2007), active contours (Ben Ayed et al., 2005; Chakraborty et al., 2009; Fu et al., 2008) and multi-objective algorithms (Collins and Kopp, 2008) may be suitable. However, it is felt that the basic premise of same-track image differencing (to mitigate incidence-angle effects and ambiguous low-backscatter response due to absorption), coupled with a 


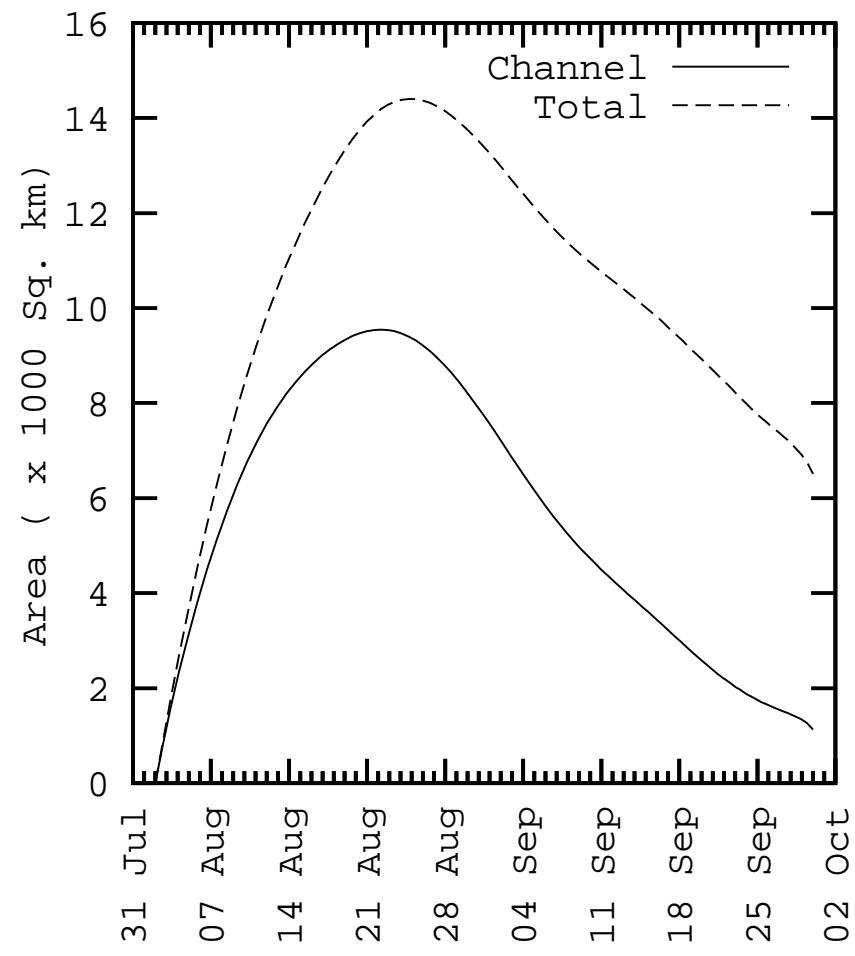

Fig. 19. Area of inundation over time, of the Indus Channel and the total flood.

robust region-growing segmentation technique (e.g. Matgen et al., 2011) to account for the small inter-modal range in the probability density functions of flooded and non-flooded areas, is well suited to map flooding in arid regions using SAR data.

\subsection{A complement to other mapping techniques}

Optical sensors, such as Landsat TM and MODIS, can easily detect open water using the strong absorption of solar energy by water in the near and middle infra-red. Shallow depths and turbid waters, are better detected at greater wavelengths ( $>1 \mu \mathrm{m}$; short-wave infra-red) where the illumination of the suspended materials or of the shallow bottom of a water column is considerably reduced (Li et al., 2003; Bukata, 2005). However during storm events the use of optical data can be severely limited by cloud cover. Radar imaging is less affected by cloud cover and can penetrate vegetation at a depth which depends on the wavelength used and the structure (density and height) of the vegetation (Hess et al., 2003; Martinez and Le Toan, 2007; Rosenqvist et al., 2007; Alsdorf et al., 2007). The use of L band data from the JERS and ALOS PALSAR sensors for flood monitoring is mainly restricted by acquisition times and limited archives, rather than by weather or vegetation condition. ALOS PALSAR data in the wide swath mode are particularly attractive to cover large regions, but unfortunately the system failed in April 2011

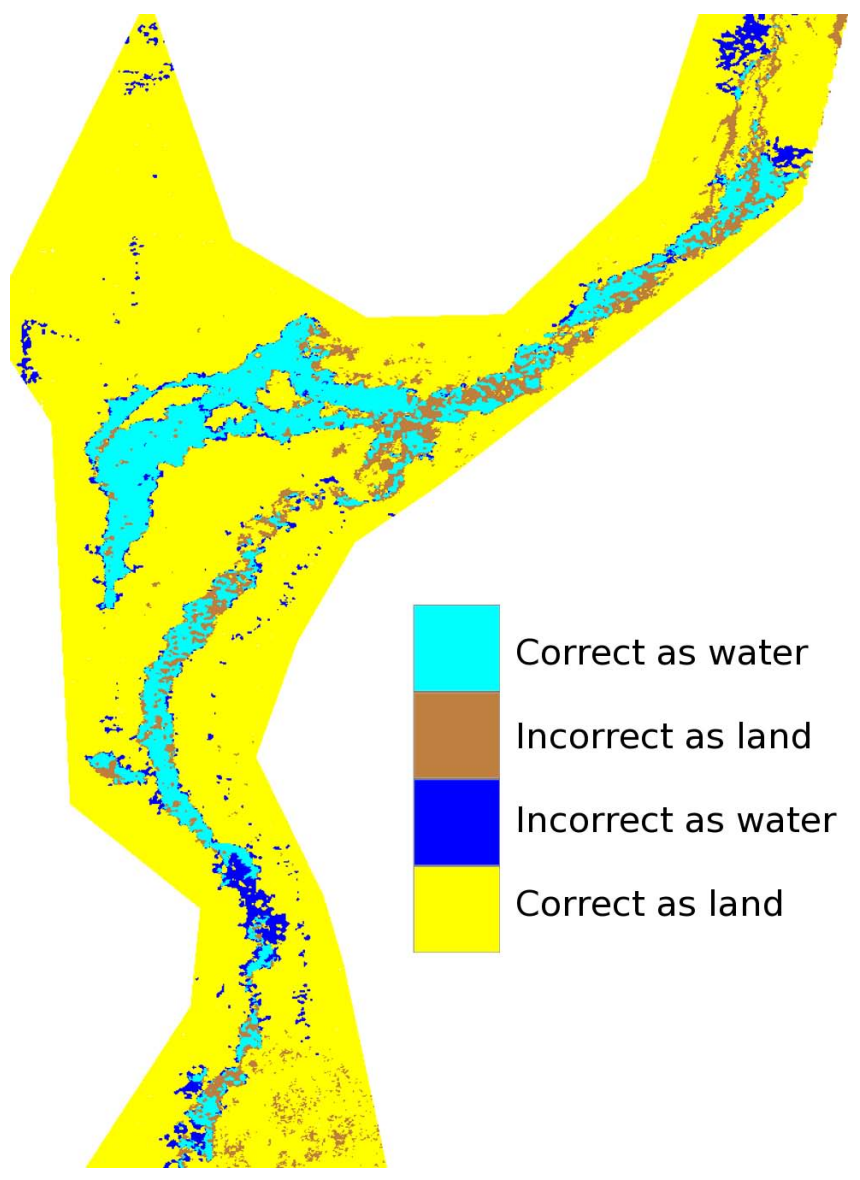

Fig. 20. Comparison of the $\Delta \sigma^{0}$-derived flood map on from $29 \mathrm{Au}$ gust 2010 against MODIS flood classification.

and this resource is therefore no longer available for data beyond that time ${ }^{4}$. Passive microwave data (e.g. SSM/I and ISCCP) are helpful for delineating inundated areas (e.g. Sippel et al., 1998; Hamilton et al., 2002), in particular when used in conjunction with other sensors to limit confounding factors such as atmospheric condition and vegetation (Prigent et al., 2007), but their use in natural disaster response is limited by their low spatial resolution (tens of $\mathrm{km}$ ). The geosynchronous weather satellites (e.g. Meteosat II, GOES, GMS) may often be able to bypass clouds with their high temporal resolution allowing for the mapping of open water at $\sim 1 \mathrm{~km}$ spatial resolution. In the specific case of flooding events occurring in semi-arid and arid regions, such as the Pakistan flood studied here, water under flooded vegetation can also be mapped using composite data from the thermal bands of these weather satellites (Leblanc et al., 2003, 2011).

Amongst the most promising potential developments in remote sensing of surface water is the future Surface Water and Ocean Topography (SWOT) mission. It is currently planned to be launched in 2020 and will provide significant

\footnotetext{
${ }^{4}$ http://www.palsar.ersdac.or.jp/e/
} 


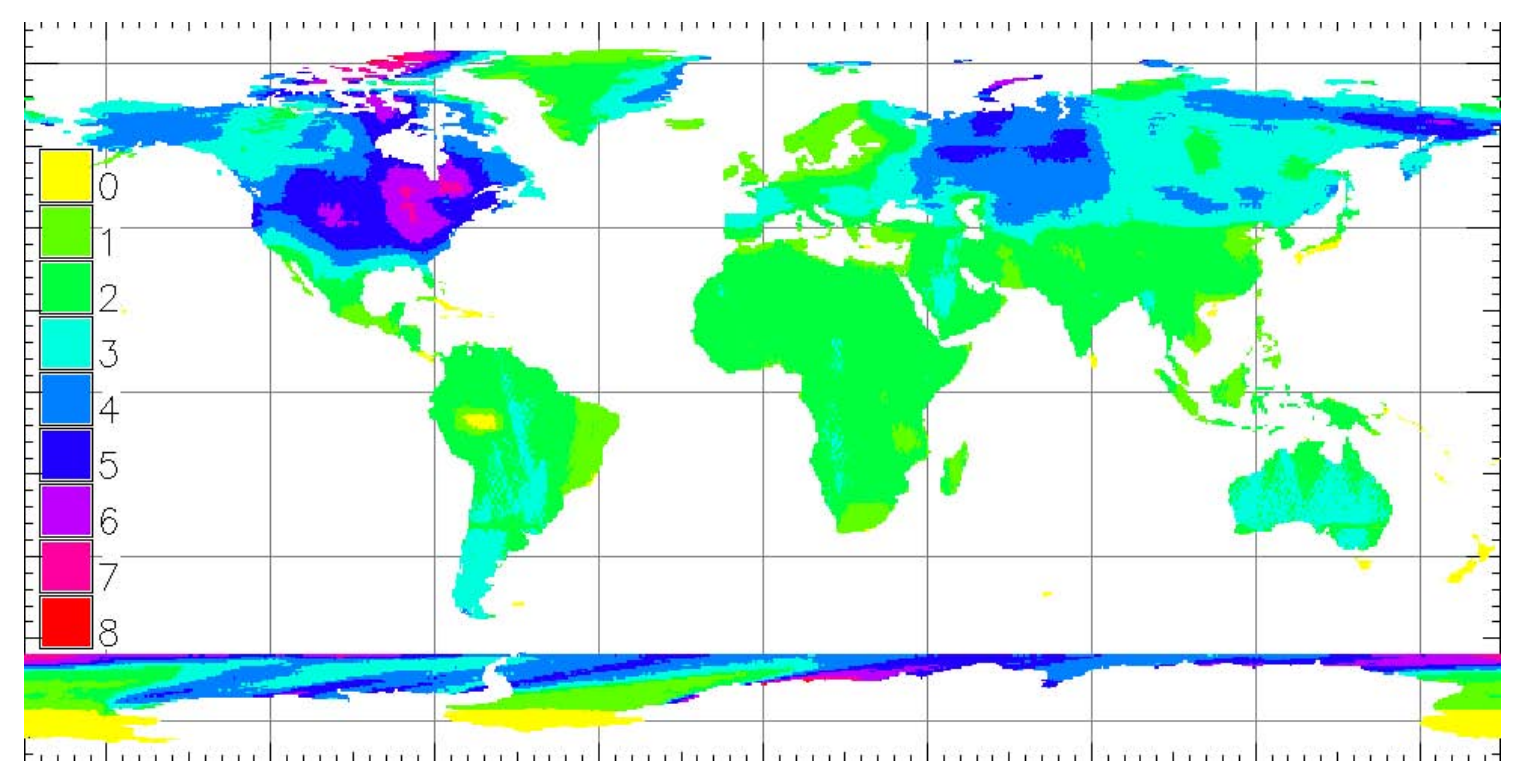

Fig. 21. Average frequency of terrestrial coverage per week by GM data between September 2009 and May 2011.

improvements in our abilities to map inundated areas from space $^{5}$. Using wide-swath altimetry technology, SWOT will provide temporal and spatial variations in water volumes stored in rivers, lakes, and wetlands at unprecedented resolution (Biancamaria et al., 2010). SWOT will generate a global 3-D mapping of all terrestrial water bodies whose surface area exceeds $250 \mathrm{~m}^{2}$ and rivers whose width exceeds $100 \mathrm{~m}$ (Biancamaria et al., 2010). The principal instrument of SWOT will be a Ka-band Radar Interferometer (KaRIN), which will provide heights and co-registered all-weather imagery of water over 2 swaths, each $60 \mathrm{~km}$ wide, with an expected precision of $1 \mathrm{~cm} \mathrm{~km}^{-1}$ for water slopes, and absolute height level precision of $10 \mathrm{~cm} \mathrm{~km}^{-2}$. ESA will also be extending and improving C-band SAR capabilities with the launch of the Sentinel-1 system, expected in 2013. This pair of satellites is planned to provide data with a spatial resolution of $20 \mathrm{~m}$, with a revisit time of between 1 and 3 days for Europe and Canada ${ }^{6}$.

\subsection{Other applications of GM data}

Space borne technologies are increasingly found to be a key source of information for wetlands conservation and management, as many of the World's wetlands have insufficient on-ground data in part due to their size, number and limited accessibility (Jones et al., 2009). Even at such a time when technological advancement in data processing, storage and communication enables ever higher spatial resolutions from airborne and satellite sensors, the use of coarser resolution data still has a very firm place in the remote sensing field where broad-scale monitoring is required, such as the monitoring of algal blooms (Ahn and Shanmugam, 2006),

\footnotetext{
${ }^{5}$ http://swot.jpl.nasa.gov/mission/

${ }^{6}$ http://www.esa.int/esaLP/SEMBRS4KXMF_LPgmes_0.html
}

assessing risks of fire (Chéret and Denux, 2007; A. and R., 2008) or drought (Rojas et al., 2011), the development of land surface models (Jarlan et al., 2005), the assessment of animal stocking rates (Hunt and Miyake, 2006) and the mapping of shorelines (M.-Muslim et al., 2007). The perceived role of GM data was primarily in the monitoring of sea ice (ESA, 2007b), to which field it has indeed contributed (e.g. Quincey and Luckman, 2009). However, its coverage and availability have already been identified as useful advantages in other areas, and have been put to good use, particularly in the areas of relative soil moisture (Bartsch et al., 2008, 2009), surface soil wetness (Pathe et al., 2009; Scipal et al., 2005) and in wetness dynamics (Scipal et al., 2005). The implication of GM data's sensitivity to surface wetness has recently led to the interesting extension to its potential use in the monitoring of freeze-thaw cycles in permafrost regions (Park et al., 2011).

The need for coarse scale inundation mapping has been identified and acted upon, resulting in, for example, the $25 \mathrm{~km}$ resolution surface water product described by Schroeder et al. (2010) which tests favourably against finer resolution products, and the $0.25^{\circ}$ global inundation map produced by Prigent et al. (2007).

This study aims to contribute to this latter group at a resolution that falls between those global-oriented scales and the finer river-channel-scale resolutions that can be achieved with other sensor-mode configurations such as JERS, ALOS PALSAR or ASAR in its finer modes. It is felt that ENVISAT ASAR GM data could be used to monitor inundation patterns over large wetlands in complement to estimates from other sensors (e.g. Sakamoto et al., 2007). 


\section{Conclusions}

It is clear that during periods of cloud cover, in which optical satellite data with which to map a flood event is not available, GM data may be available to varying degrees that cover the region of interest. Much of the rain (and the cloud) that affects flooding in Pakistan occurs in the mountains away from the flood plain, and so it is fair to say that the relative availability of GM data with optical data may be greater in flood events elsewhere, making the use of GM data of greater value.

Ambiguity resulting from low backscatter values from non-flooded areas have been shown to have been reduced greatly by the image differencing process, as these low backscatter values are reasonably consistent between orbit cycles. A greater challenge is presented by the ambiguities in origin of data values, where effects such as dihedral scattering, Bragg resonance and speckle can raise and lower pixel values and prohibit the accurate classification of water. Where the objective is to ascertain the extent of flooding in near real time, there is little that can be done about Bragg resonance unless precise wind conditions are known, other than to hope that temporal frequency of data is sufficient to allow us to understand where this effect may have occurred and to rectify it in an updated image. The effects of speckle can be reduced with filtering. Dihedral scattering can, to some extent, be managed by acceptance that only open water is being mapped, or by further analysis using textural measures. Where, for example, dihedral scattering is dominant in a pixel, we expect the $\Delta \sigma^{0}$ value to be high, and would expect such areas of partial inundation to surround areas of total inundation. Further analysis could therefore encompass such regions into the flooded class and improve the overall accuracy. The coarse spatial resolution of GM data compounds all of the above problems, where adjacent regions of low and high backscatter values return an averaged mid-range value.

It has been shown, however, that a reasonable level of overall accuracy can be achieved using GM data which allows an understanding of the dynamics and broad-scale extents of a large flood during periods when there are no other means by which to judge these parameters. In the interests of flood mitigation planning, where thousands of lives are at stake, we feel that the potential use of GM data for this purpose is significant.

Acknowledgements. This project was partly funded by a Discovery grant (DP110103364) from the Australian Research Council. Thanks go also to the European Space Agency for the provision of all radar data, under the project number C1P.5908.

Edited by: W. Wagner

\section{References}

Lanorte, A. and Lasaponara, R.: Fuel type characterization based on coarse resolution MODIS satellite data, iForest - Biogeosciences and Forestry, 1, 60-64, 2008.

Ahn, Y.-H. and Shanmugam, P.: Detecting the red tide algal blooms from satellite ocean color observations in optically complex Northeast-Asia Coastal waters, Remote Sens. Environ., 103, 419-437, 2006.

Alpers, W.: Theory of radar imaging of internal waves, Nature, 314, 245-247, 1985.

Alsdorf, D., Rodriguez, E., and Lettenmaier, D.: Measuring surface water from space, Rev. Geophys., 45, 1-24, 2007.

Ashraf, M. and Majeed, A.: Water requirements of major crops for different agro-climatic zones of Balochistan, vol. vii, The World Conservation Union (IUCN) Pakistan, Water Programme., Marker House, Zarghoon Road, Quetta, Pakistan, 2006.

Baghdadi, N., Bernier, M., Gauthier, R., and Neeson, I.: Evaluation of C-band SAR data for wetlands mapping, Int. J. Remote Sens., 22, 71-88, 2001.

Bartsch, A., Doubkova, M., Pathe, C., Sabel, D., Wagner, W., and Wolski, P.: River Flow \& Wetland Monitoring with Envisat ASAR global mode in the Okavango Basin and Delta, in: Proceedings of the Second IASTED Africa Conference Water Resource Management (AfricaWRM 2008), 152-156, Gaborone, Botswana, 2008.

Bartsch, A., Wagner, W., Scipal, K., Pathe, C., Sabel, D., and Wolski, P.: Global monitoring of wetlands - the value of ENVISAT ASAR Global mode, J. Environ. Manage., 90, 22262233, doi:10.1016/j.jenvman.2007.06.023, 2009.

Ben Ayed, I., Mitiche, A., and Belhadj, Z.: Multiregion level-set partitioning of synthetic aperture radar images, United States, IEEE Computer Soc., 27, 793-800, 2005.

Biancamaria, S., Andreadis, K. M., Durand, M., Clark, E. A., Rodriguez, E., Mognard, N. M., Alsdorf, D. E., Lettenmaier, D. P., and Oudin, Y.: Preliminary Characterization of SWOT Hydrology Error Budget and Global Capabilities, IEEE J. Sel. Top. Appl., 3, 6-19, 2010.

Bukata, R.: Satellite Monitoring of Inland and Coastal Water Quality: Retrospection, Introspection, Future Directions, Taylor and Francis, New York, 2005.

Chakraborty, D., Sen, G., and Hazra, S.: High-resolution satellite image segmentation using Holder exponents, J. Earth Syst. Sci., 118, 609-617, 2009.

Chen, J. M., Chen, X., Ju, W., and Geng, X.: Distributed hydrological model for mapping evapotranspiration using remote sensing inputs, J. Hydrol., 305, 15-39, 2004.

Chéret, V. and Denux, P.: Mapping wildfire danger at regional scale with an index model integrating coarse spatial resolution remote sensing data, J. Geophys. Res., 112, G02006, doi:10.1029/2005JG000125, 2007.

Cohen, J.: A Coefficient of Agreement for Nominal Scales, Educ. Psychol. Meas., XX, 37-46, 1960.

Collins, M. J. and Kopp, E. B.: On the Design and Evaluation of Multiobjective Single-Channel SAR Image Segmentation Algorithms, IEEE T. Geosci. Remote Sens., 46, 1836-1846, 2008.

Conesa-Garcia, C., Caselles-Miralles, V., Sanchez Tomas, J. M., and Garcia-Lorenzo, R.: Hydraulic Geometry, GIS and Remote Sensing, Techniques against Rainfall-Runoff Models for Estimating Flood Magnitude in Ephemeral Fluvial Systems, Remote 
Sens., 2, 2607-2628, 2010.

Decharme, B., Ottlé, C., Saux-Picart, S., Boulain, N., Cappelaere, B., Ramier, D., and Zribi, M.: A New Land Surface Hydrology within the Noah-WRF Land-Atmosphere Mesoscale Model Applied to Semiarid Environment: Evaluation over the Dantiandou Kori (Niger), Advances in Meteorology, 2009, 731874, doi:10.1155/2009/731874, 2009.

Dheeravath, V., Thenkabail, P., Chandrakantha, G., Noojipady, P., Reddy, G., Biradar, C., Gumma, M., and Velpuri, M.: Irrigated areas of India derived using MODIS $500 \mathrm{~m}$ time series for the years 2001-2003, ISPRS J. Photogramm., 65, 42-59, doi:10.1016/j.isprsjprs.2009.08.004, 2010.

ESA: Absolute calibration of ASAR level 1 products generated with PF-ASAR, European Space Agency, ESRIN, Via Galileo Galilei, Casella Postale 64, 00044 Frascati (Rome), Italy, 1.5 Edn., 2004.

ESA: ASAR Product Handbook, European Space Agency, 8-10 rue Mario Nikis, 75738 Paris, 2.2 Edn., 2007a.

ESA: Asar Products Specifications, in: Envisat-1 Products Specifications, 8, 2007b.

Fair, C. C.: Pakistan in 2010 Flooding, Governmental Inefficiency, and Continued Insurgency, Asian Surv., 51, 97-110, 2011.

Foody, G. M.: What is the difference between two maps? A remote sensers view, J. Geogr. Syst., 8, 119-130, 2006.

Fu, Y., Cao, Z., and Pi, Y.: Multi-region segmentation of SAR image by a multiphase level set approach, J. Electron. (China), 25, 556-561, 2008.

Galland, F., Nicolas, J., Sportouche, H., Roche, M., Tupin, F., and Refregier, P.: Unsupervised Synthetic Aperture Radar Image Segmentation Using Fisher Distributions, IEEE T. Geosci. Remote Sens., 47, 2966-2972, 2009.

GESDISC: Flooding in Pakistan caused by higher-than-normal monsoon rainfall, Goddard Earth Sciences Data and Information Services Center, available at: http://disc.sci.gsfc.nasa.gov, last access: 1 March 2011, 2011.

GRASS Development Team: Geographic Resources Analysis Support System (GRASS GIS) Software, Open Source Geospatial Foundation, USA, available at: http://grass.osgeo.org, last access: 15 October 2011, 2009.

Hamilton, S., Sippel, S., and Melack, J.: Comparison of inundation patterns among major South American floodplains, J. Geophys. Res. Atmos., 107, 8038, doi:10.1029/2000JD000306, 2002.

Hess, L. L., Melack, J. M., Novo, E. M., Barbosa, C. C., and Gastil, M.: Dual-season mapping of wetland inundation and vegetation for the central amazon basin, Remote Sens. Environ., 87, 404428, 2003

Hostache, R., Matgen, P., Schumann, G., Puech, C., Hoffmann, L., and Pfister, L.: Water Level Estimation and Reduction of Hydraulic Model Calibration Uncertainties Using Satellite SAR Images of Floods, IEEE T. Geosci. Remote Sens., 47, 431-441, 2009.

Hunt, E. R. and Miyake, B. A.: Comparison of Stocking Rates From Remote Sensing and Geospatial Data, Rangeland Ecol. Manag., 59, 11-18, 2006.

Hunt, E. R., Gillham, J., and Daughtry, C.: Improving Potential Geographic Distribution Models for Invasive Plants by Remote Sensing, Rangeland Ecol. Manag., 63, 505-513, 2010.

Jarlan, L., Mougin, E., Mazzega, P., Schoenauer, M., Tracol, Y., and Hiernaux, P.: Using coarse remote sensing radar observations to control the trajectory of a simple Sahelian land surface model, Remote Sens. Environ., 94, 269-285, doi:10.1016/j.rse.2004.10.005, 2005.

Jarvis, A., Reuter, H., Nelson, A., and Guevara, E.: Hole-filled seamless SRTM data V4, International Centre for Tropical Agriculture (CIAT), available at: http://srtm.csi.cgiar.org, last access: 15 May 2011, 2008.

Jones, K., Lanthier, Y., van der Voet, P., van Valkengoed, E., Taylor, D., and Fernandez-Prieto, D.: Monitoring and assessment of wetlands using Earth Observation: The GlobWetland project, J. Environ. Manage., 90, 2154-2169, 2009.

Leblanc, M., Razack, M., Dagorne, D., Mofor, L., and Jones, C.: Application of Meteosat thermal data to map soil infiltrability in the central part of the Lake Chad basin, Africa, Geophys. Res. Lett., 30, 19, doi:10.1029/2003GL018094, 2003.

Leblanc, M., Lemoalle, J., Bader, J.-C., Tweed, S., and Mofor, L.: Thermal remote sensing of water under flooded vegetation: new observations of inundation patterns for the 'Small' Lake Chad, J. Hydrol., 404, 87-98, doi:10.1016/j.jhydrol.2011.04.023, 2011.

Li, R.-R., Kaufman, Y., Gao, B.-C., and Davis, C.: Remote sensing of suspended sediments and shallow coastal waters, IEEE T. Geosci. Remote Sens., 41, 559-566, 2003.

Liebe, J. R., van de Giesen, N., Andreini, M. S., Steenhuis, T. S., and Walter, M. T.: Suitability and Limitations of ENVISAT ASAR for Monitoring Small Reservoirs in a Semiarid Area, IEEE T. Geosci. Remote Sens., 47, 1536-1547, 2009.

Liu, Q., Wang, M., and Zhao, Y.: Assimilation of ASAR data with a hydrologic and semi-empirical backscattering coupled model to estimate soil moisture, Chinese Geogr. Sci., 20, 218-225, 2010.

Ludwig, R. and Schneider, P.: Validation of digital elevation models from SRTM X-SAR for applications in hydrologic modeling, ISPRS J. Photogramm., 60, 339-358, 2006.

M.-Muslim, A., Foody, G. M., and Atkinson, P. M.: Shoreline Mapping from CoarseSpatial Resolution Remote Sensing Imagery of Seberang Takir, Malaysia, J. Coastal Res., 23, 1399-1408, doi:10.2112/04-0421.1, 2007.

Martinez, J.-M. and Le Toan, T.: Mapping of flood dynamics and spatial distribution of vegetation in the Amazon floodplain using multitemporal SAR data, Remote Sens. Environ., 108, 209-223, 2007.

Matgen, P., Hostache, R., Schumann, G., Pfister, L., Hoffmann, L., and Savenije, H.: Towards an automated SARbased flood monitoring system: Lessons learned from two case studies, Phys. Chem. Earth, Parts A/B/C, 36, 241-252, doi:10.1016/j.pce.2010.12.009, 2011.

Milzow, C., Kgotlhang, L., Bauer-Gottwein, P., Meier, P., and Kinzelbach, W.: Regional review: the hydrology of the Okavango Delta, Botswana-processes, data and modelling, Hydrogeol. J., 17, 1297-1328, 2009a.

Milzow, C., Kgotlhang, L., Kinzelbach, W., Meier, P., and BauerGottwein, P.: The Role of remote sensing in hydrological modelling of the Okavango Delta, Botswana, J. Environ. Manage., 90, 2252-2260, 2009b.

Monsiváis, A., Chênerie, I., Baup, F., Mougin, E., and Sarabandi, K.: Angular Normalization of ENVISAT ASAR Data over Sahelian-grassland Using a Coherent Scattering Model, in: Progress In Electromagnetics Research Symposium, Cambridge, USA, 2006.

Montanari, M., Hostache, R., Matgen, P., Schumann, G., Pfister, L., and Hoffmann, L.: Calibration and sequential updating 
of a coupled hydrologic-hydraulic model using remote sensingderived water stages, Hydrol. Earth Syst. Sci., 13, 367-380, doi:10.5194/hess-13-367-2009, 2009.

NDMA: Pakistan floods relief, recovery and rehabilitation, National Disaster Management Authority, Prime Minister's Secretariat, Government of Pakistan, available at: http://www.pakistanfloods. pk/, last access: 11 February 2011, 2011.

Ordoyne, C. and Friedl, M. A.: Using MODIS data to characterize seasonal inundation patterns in the Florida Everglades, Remote Sens. Environ., 112, 4107-4119, doi:10.1016/j.rse.2007.08.027, 2008.

Park, S.-E., Bartsch, A., Sabel, D., Wagner, W., Naeimi, V., and Yamaguchi, Y.: Monitoring freeze/thaw cycles using ENVISAT ASAR Global Mode, Remote Sens. Environ., in press, doi:10.1016/j.rse.2011.08.009, 2011.

Pathe, C., Wagner, W., Sabel, D., Doubkova, M., and Basara, J. B.: Using ENVISAT ASAR Global Mode Data for Surface Soil Moisture Retrieval Over Oklahoma, USA, IEEE T. Geosci. Remote Sens., 47, 468-480, 2009.

Pauwels, V. R. N., Balenzano, A., Satalino, G., Skriver, H., Verhoest, N. E. C., and Mattia, F.: Optimization of Soil Hydraulic Model Parameters Using Synthetic Aperture Radar Data: An Integrated Multidisciplinary Approach, IEEE T. Geosci. Remote Sens., 47, 455-467, 2009.

Prigent, C., Papa, F., Aires, F., Rossow, W. B., and Matthews, E.: Global inundation dynamics inferred from multiple satellite observations, 1993-2000, J. Geophys. Res., 112, 1-13, 2007.

Quincey, D. and Luckman, A.: Progress in satellite remote sensing of ice sheets, Prog. Phys. Geog., 33, 547-567, doi:10.1177/0309133309346883, 2009.

Reuter, H., Nelson, A., and Jarvis, A.: An evaluation of void filling interpolation methods for SRTM data, Int. J. Geogr. Inf. Sci., 21, 983-1008, 2007.

Robinson, C., El-Baz, F., Al-Saud, T., and Jeon, S.: Use of radar data to delineate palaeodrainage leading to the Kufra Oasis in the eastern Sahara, J. Afr. Earth Sci., 44, 229-240, 2006.

Rojas, O., Vrieling, A., and Rembold, F.: Assessing drought probability for agricultural areas in Africa with coarse resolution remote sensing imagery, Remote Sens. Environ., 115, 343-352, doi:10.1016/j.rse.2010.09.006, 2011.

Rosenquist, A., Finlayson, C. M., Lowry, J., and Taylor, D.: The potential of long-wavelength satellite-borne radar to support implementation of the Ramsar Wetlands Convention, Aquatic Conserv: Mar. Freshw. Ecosyst., 17, 229-244, doi:10.1002/aqc.835, 2007.

Sakamoto, T., Van Nguyen, N., Kotera, A., Ohno, H., Ishitsuka, N., and Yokozawa, M.: Detecting temporal changes in the extent of annual flooding within the Cambodia and the Vietnamese Mekong Delta from MODIS time-series imagery, Remote Sens. Environ., 109, 259-313, 2007.

Sanyal, J. and Lu, X. X.: Application of Remote Sensing in Flood Management with Special Reference to Monsoon Asia: A Review, Nat. Hazards, 33, 283-301, 2004.

Saux-Picart, S., Ottlé, C., Decharme, B., André, C., Zribi, M., Perrier, A., Coudert, B., Boulain, N., Cappelaere, B., Descroix, L., and Ramier, D.: Water and energy budgets simulation over the AMMA-Niger super-site spatially constrained with remote sensing data, J. Hydrol., 375, 287-295, 2009.
Schaber, G. G., McCauley, J. F., and Breed, C. S.: The Use of Multifrequency and Polarimetric SIR-C/X-SAR Data in Geologic Studies of Bir Safsaf, Egypt, Remote Sens. Environ., 59, 336363, 1997.

Schiermeier, Q.: Increased flood risk linked to global warming, Nature, 470, 316, doi:10.1038/470316a, 2011.

Schroeder, R., Rawlins, M. A., McDonald, K. C., Podest, E., Zimmermann, R., and Kueppers, M.: Satellite microwave remote sensing of North Eurasian inundation dynamics: development of coarse-resolution products and comparison with high-resolution synthetic aperture radar data, Environ. Res. Lett., 5, 015003, doi:10.1088/1748-9326/5/1/015003, 2010.

Schumann, G., Matgen, P., Hoffmann, L., Hostache, R., Pappenburger, F., and Pfister, L.: Deriving distributed roughness values from satellite radar data for flood inundation modelling, J. Hydrol., 344, 96-111, 2007.

Scipal, K., Scheffler, C., and Wagner, W.: Soil moisture-runoff relation at the catchment scale as observed with coarse resolution microwave remote sensing, Hydrol. Earth Syst. Sci., 9, 173-183, doi:10.5194/hess-9-173-2005, 2005.

Silveira, M. and Heleno, S.: Separation Between Water and Land in SAR Images Using Region-Based Level Sets, IEEE Geosci. Remote Sens. Lett., 6, 471-475, 2009.

Sippel, S., Hamilton, S., Melack, J., and Novo, E.: Passive microwave observations of inundation area and the area/stage relation in the Amazon River floodplain, Int. J. Remote Sens., 19, 3055-3074, 1998.

Stisen, S., Jensen, K. H., Sandholt, I., and Grimes, D. I. F.: A remote sensing driven distributed hydrological model of the Senegal River basin, J. Hydrol., 354, 131-148, 2008.

Tolpekin, V. A., Stein, A., and Stein, A.: Quantification of the Effects of Land-Cover-Class Spectral Separability on the Accuracy of Markov-Random-Field-Based Superresolution Mapping, PISCATAWAY, IEEE T. Geosci. Remote Sens., 47, 3283-3297, 2009.

Ulaby, F. T., Moore, R. K., and Fung, A. K.: Radar Remote Sensing and Surface Scattering and Emission Theory, Vol. 2, AddisonWesley, New York, 1982.

van der Werff, H. M. A. and van der Meer, F. D.: Shape-based classification of spectrally identical objects, ISPRS J. Phoyogramm., 63, 251-258, 2007.

Waisurasingha, C., Aniya, M., Hirano, A., Kamusoko, C., and Sommut, W.: Application of C-band Synthetic Aperture Radar Data and Digital Elevation Model to Evaluate the Conditions of Flood-Affected Paddies: Chi River Basin, Thailand, in: Asian Association on Remote Sensing, Proceedings ACRS 2007, available at: http://www.a-a-r-s.org/acrs/proceeding/ACRS2007/ Papers/PS1.G5.4.pdf, last access: 20 June 2011, 2007.

WBG: Pakistan Floods 2010: Preliminary Damage and Needs Assessment, in: Pakistan, The World Bank, available at: http://go. worldbank.org/OL97TLRN30, last access: 15 May 2011, 2011.

Wilson, B. A. and Rashid, H.: Monitoring the 1997 flood in the Red River valley, Can. Geogr., 49, 100-109, 2005.

Yu, Q. and Clausi, D.: SAR Sea-Ice Image Analysis Based on Iterative Region Growing Using Semantics, IEEE T. Geosci. Remote Sens., 45, 3919-3931, 2007. 